\title{
Les vides sanitaires et les amphores de la Porte d'Orée à Fréjus (Var)
}

\author{
par Fanette LAUBENHEIMER * \\ avec la collaboration de Isabelle BÉRAUD et Chérine GÉBARA**
}

A Fréjus, dans les fouilles de la Porte d'Orée, deux vides sanitaires, l'un des années 30, l'autre flavien, ont îné une série exceptionnellement bien conservée de 95 amphores.

Le système d'assainissement est. l'occasion de faire le point sur ce recyclage spécifique des amphores, lê. Gement développé en Italie, mais utilisé en Gaule de très longue date. Il présente ici quelque particularité.

Les amphores révèlent de nouvelles productions locales - amphore à fond plat tibérienne, variante de Dr. 14 (?) et une importante série de Dr. 2/4 - qui élargissent considérablement la gamme des fabrications fréjusiennes. La production locale et l'exportation de vin et de poisson salé ou en sauce se pose en termes nouveaux.

In Fréjus Porte d'Orée excavations, two underfloor spaces (30 A.D. and flavian period) kept very well preserved 95 amphoras.

This specific system of purification with re-used amphoras, is well known in Italy, but frequent in Gaul as well since a long time. The Fréjus one has distinctive signs.

New local amphoras productions - tiberian flat boltom ones, Dr. 14 variant and a whole series of Dr. 2/4 make the Fréjus list much more important. Wine and fish local productions as well as exports, have to be seen now in different terms.

Mots clés : vide sanitaire, amphores, productions locales, vin, poisson, $\mathrm{I}^{\text {er }}$ s., Porte d'Orée, Fréjus, Var.

* C.NRS, URA 338, 30, rue Mégevand, 25030 Besançon Cedex.

** Service archéologique municipal de Fréjus, Mairie de Fréjus, BP 108, 83608 Fréjus Cedex. 


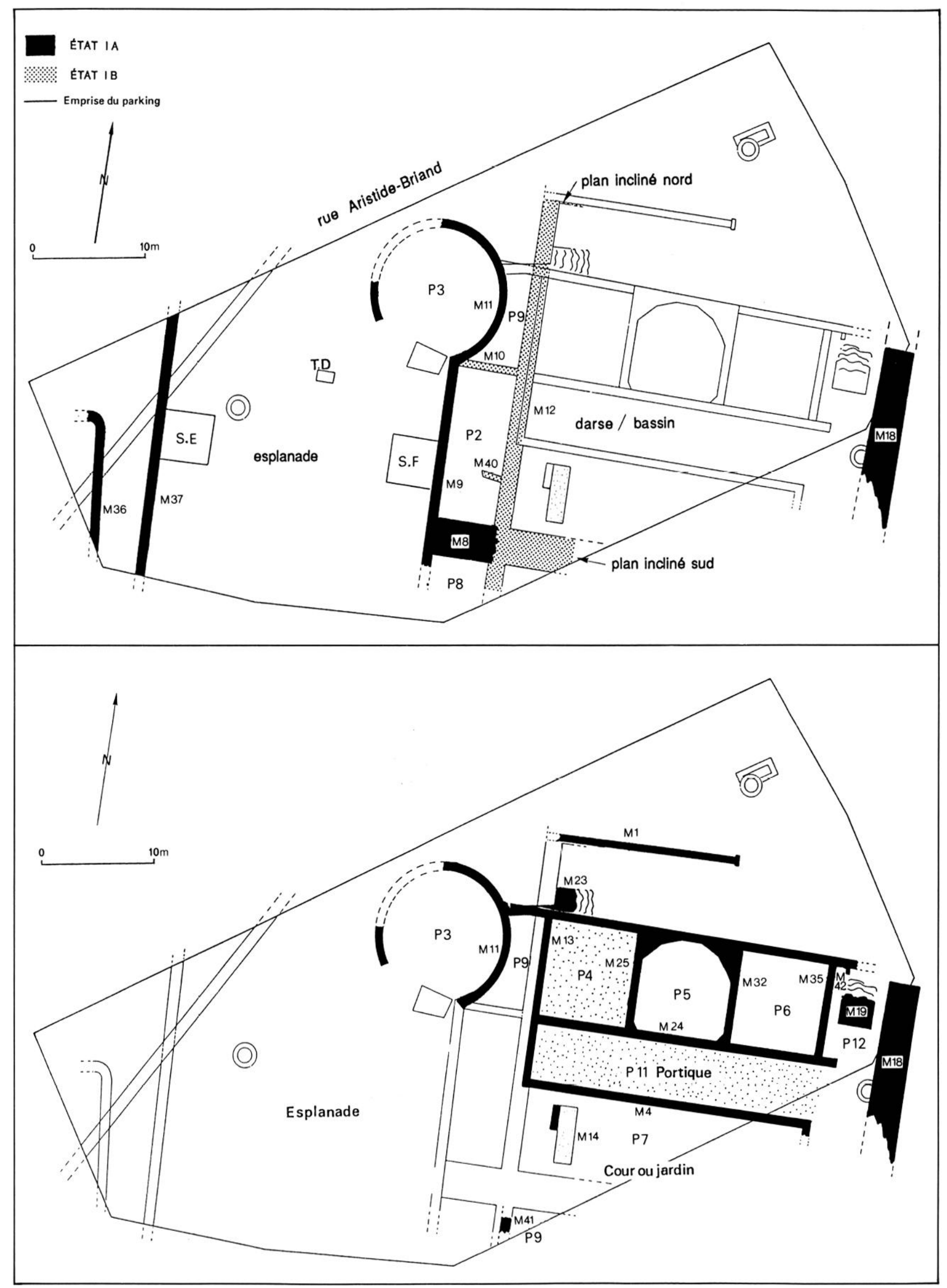

Fig. 1 - Plans du quartier de la Porte d'Orée. En haut, état I : localisation du bassin et de l'esplanade avec les sondages I), E, F ; en bas, état II : localisation des zones P7 et P13. 
Les fouilles de sauvetage menées à la Porte d'Orée, à Fréjus, ont conduit à l'exploration partielle de deux installations de drainage aménagées dans des bâtiments importants du quartier du port, au $\mathrm{I}^{\text {er }} \mathrm{s}$. de notre ère ${ }^{1}$. Comme souvent dans ce genre de construction, on a réutilisé des amphores. On en compte ici près d'une centaine, souvent entières et de diverses formes. Ce matériel exceptionnel par sa qualité, sa quantité et sa variété est, en outre, rassemblé dans des milieux clos. Ce qu'il apporte renouvelle la connaissance de la circulation des amphores à Fréjus; plus encore, et c'est une surprise, nous y découvrons tout un pan de la production d'amphores fréjusiennes, complètement ignoré jusqu'alors : il fait apparaitre en termes nouveaux l'activité marchande et agricole de la ville et de sa région.

\section{L'AMÉNAGEMENT DES VIDES SANITAIRES}

Deux systèmes de drainage indépendants, mais voisins ont été construits à des périodes différentes. Tous les deux sont équipés d'amphores en couches superposées homogènes, scellées par des niveaux de remblai et d'occupation.

1 Voir supra, p. 165-228, l'article de Ch. Gímara, I. Béraud et C. Landurf́. La Porte d'Orée : transformations el avatars d'un secteur portuaire à Fréjus (Var), d'où je tire les grandes lignes de l'évolution du quartier et la description de la fouille.

\section{LE DRAINAGE DE L'ESPLANADE}

Lors de la première phase de construction du secteur de la ville que diverses données concordantes de la fouille autorisent à dater des années 30 de notre ère, on aménage une large esplanade longeant un bassin du port (fig. 1). Elle est délimitée par deux murs parallèles (M 37 et M 9), distants de $24,50 \mathrm{~m}$; pour des raisons évidentes de remontée d'eau, il a été nécessaire de mettre en place un système de drainage. Un sondage situé à l'est, contre le mur 9 , a mis en évidence, sur $8 \mathrm{~m}^{2}$, la partie supérieure d'un vide sanitaire composé d'amphores dont le fond, noyé par l'affleurement de la nappe phréatique, n'a pu être atteint (fig. 2). Le niveau de l'eau n'est pas le mème aujourd'hui, comme il a été démontré ailleurs. In sondage très restreint (D), au nord de l'esplanade, a touché ponctuellement la couche du drainage d'amphores, tandis que, vers l'ouest, un autre sondage (E) est resté trop superficiel pour y parvenir. On peut vraisemblablement envisager que la totalité de l'esplanade a été assainie. Si l'on estime, d'après le sondage $\mathrm{F}$, que le vide sanitaire comporte un minimum de deux amphores par mètres carrés (hypothèse basse, avec un seul niveau d'amphores), la surface explorée de l'esplanade étant de l'ordre de $450 \mathrm{~m}^{2}$. c'est par centaines, voire par milliers, que les amphores ont été réutilisées ici. Les $8 \mathrm{~m}^{2} \mathrm{du}$ sondage F offrent un échantillonnage limité de dix-sept individus au minimum, qui a le mérite de compter des objets relativement bien conservés et parfois entiers. dans un milieu clos.

Les amphores sont disposées la tête en bas pour la plupart, parfois le col vers le haut; inclinées du

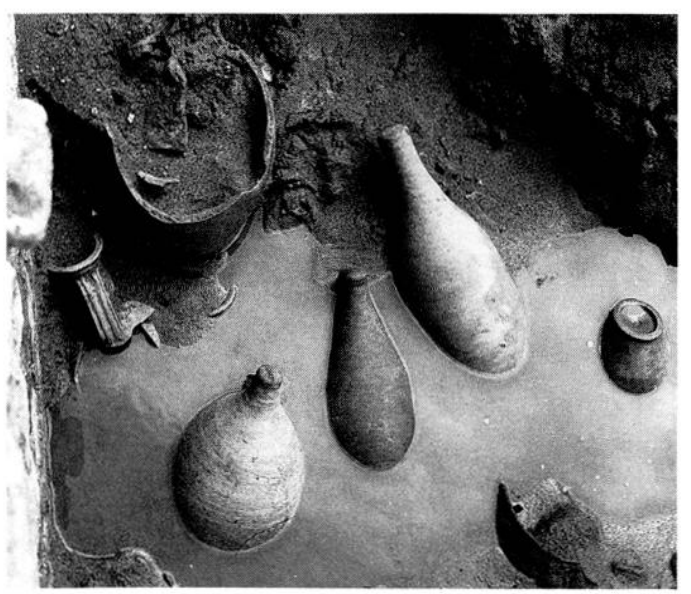

Fig. $2-A$ gauche, vue des amphores du vide sanitaire de l'esplanade dans le sondage $\mathrm{F}$; à droite, coupe du sondage $\mathrm{F}$.

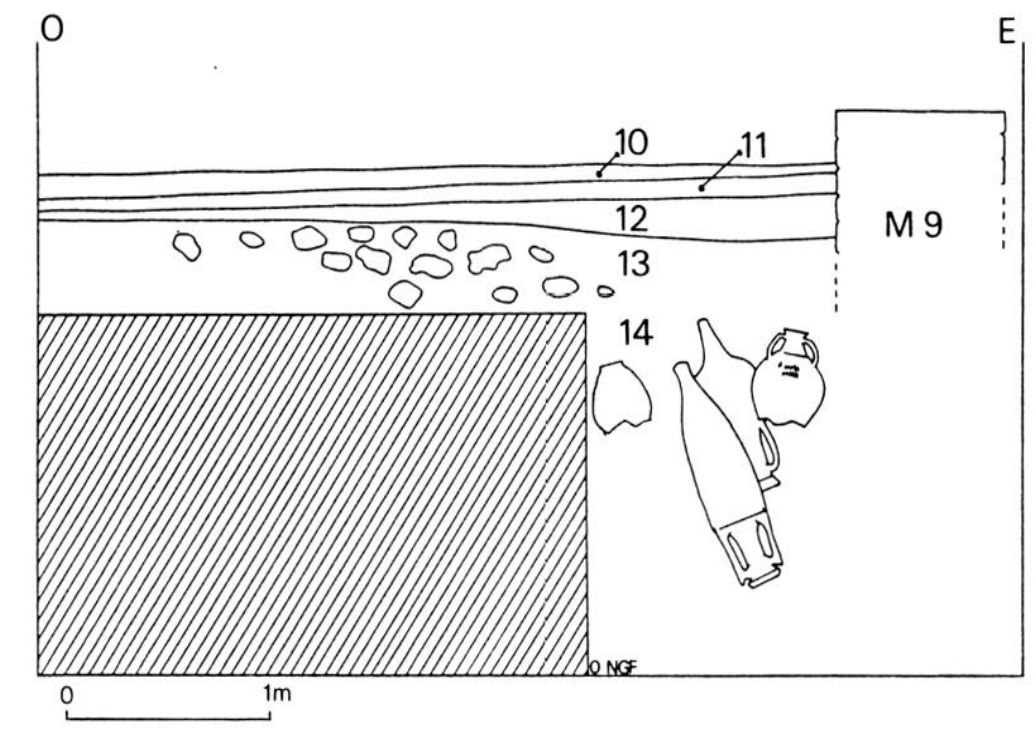




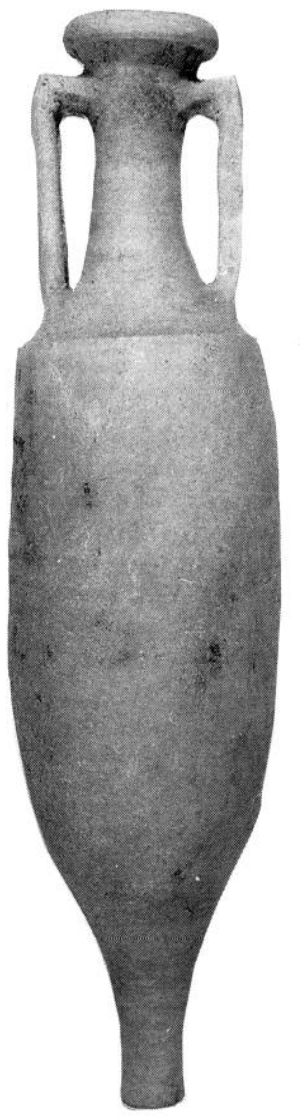

SF. 02

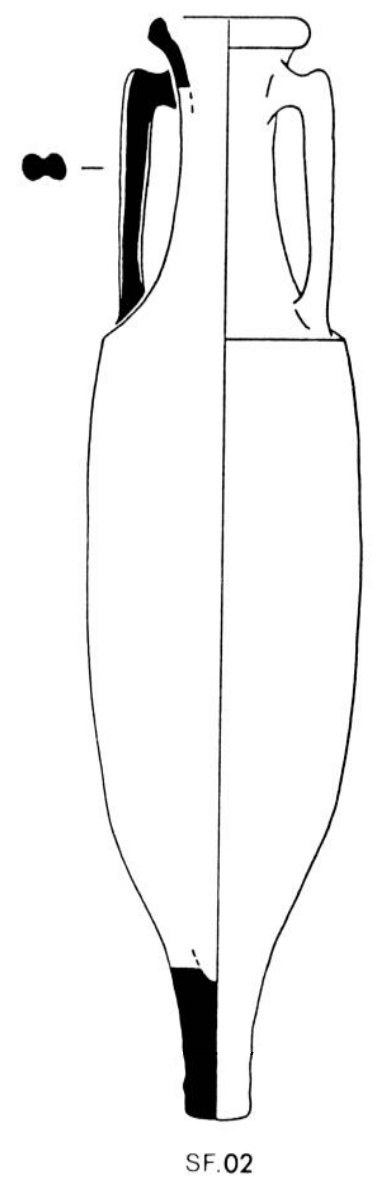

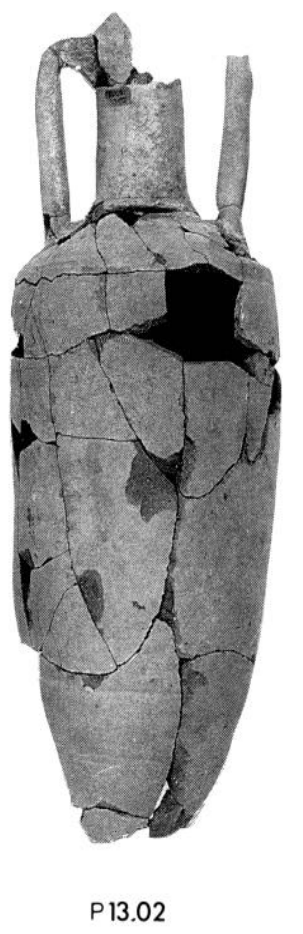

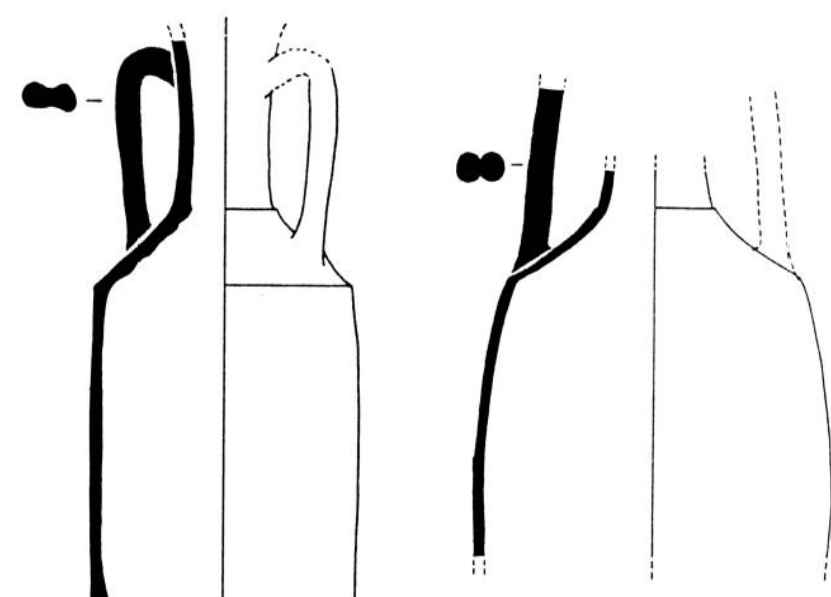

SF.06 

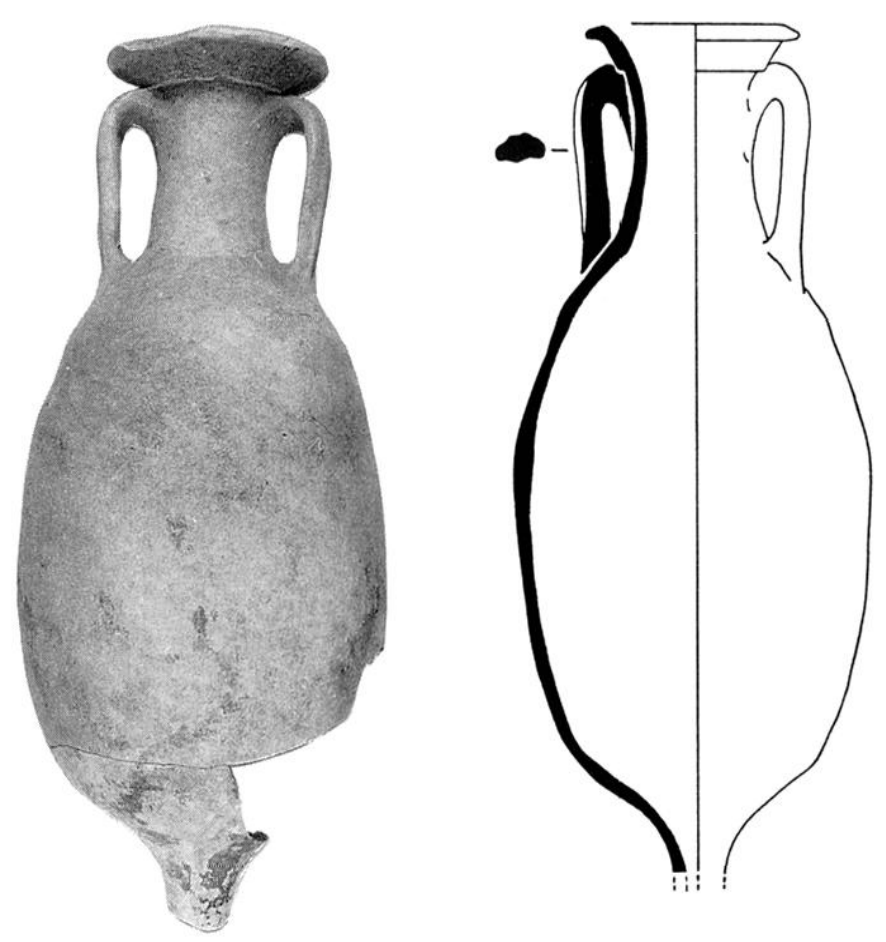

SF.07
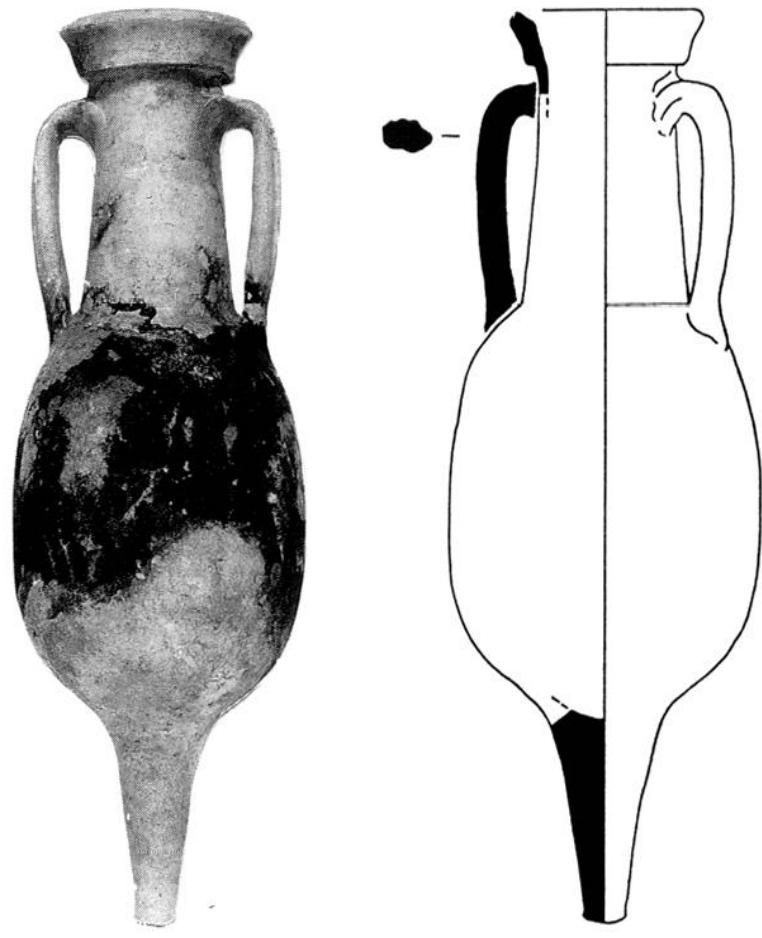

SD

Fig. 4 - Amphores Dr. 7 du vide sanitaire de l'esplanade. (Échelle 1/10).

sud vers le nord, ou presque verticales, elles viennent s'aligner sur le mur 9. Elles sont noyées dans une couche de sable. On trouve un mélange de formes longues surtout (Dr. 2/4, I)r. 7/11) el rondes (Dr. 20) et quelques amphores à fond plat ou des cruches, plus légères et fragiles. Le sondage D n'a fourni qu'une seule amphore, entière, de forme Dr. 7.

\section{Catalogue des amphores DU VIDE SANITAIRE DE L'ESPLANADE}

\section{SONDAGES F ET $D^{2}$}

Les références d'origine, signalées par un *, renvoient aux analyses de pâte par fluorescence $X$ qui sont présentées dans l'annexe I, p. 257.

2 Pour l'ensemble du matériel des vides sanitaires, la description de la pâte n'est pas donnée pour les amphores de grandes séries bien connues (Dr. 20, Dr. 7/11 ...). La plupart des amphores étaient brisées sur place. Le travail remarquable de recollage mené par Albert Conte, technicien au Service archéologique municipal de Fréjus, et Danièle RaizelsonBarbe, restauratrice, livre à l'étude un échantillonnage exceptionnel d'objets entiers reconstitués.

\section{Dressel $2 / 4$}

Inv. SF. 02 : amphore entière (fig. 3), pâte beige orangé, poids : $14,5 \mathrm{~kg}$, contenance : $21,5 \mathrm{l}$.

Inv. SF. 03* : bas du col, panse et fond (lig. 16), uII cercle au bas du col, pâte rouge, riche en inclusions. Origine vraisemblable : Tarraconaise.

Inv. $S F .06^{*}$ : haut de panse et bas du col (fig. 3), un cercle à la liaison col-panse, pâte brun-rose, très chargée en inclusions noires brillantes. Origine: région de Pompéi.

Inv. $S F \cdot 16^{*}$ : amphore complète sauf le bas de la panse et le fond (fig. 3), pâte orangée avec fines inclusions blanches, n’appartient pas à la région de Fréjus d'après sa composition.

\section{Dressel 7}

Inv. SF. 07 : amphore complète sauf la pointe (fig. 4), pâte beige, anse à trois sillons.

Inv. $S D$ : amphore complète (fig. 4), poids : $15 \mathrm{~kg}$. contenance : $20.7 \mathrm{l}$.

\section{Dressel $7 / 11$}

Inv. SF, 10 : panse et fond.

Inv. SF. 11 : bas de panse.

Inv. SF, 14A : panse complète avec départ de fond creux, pâte beige. 

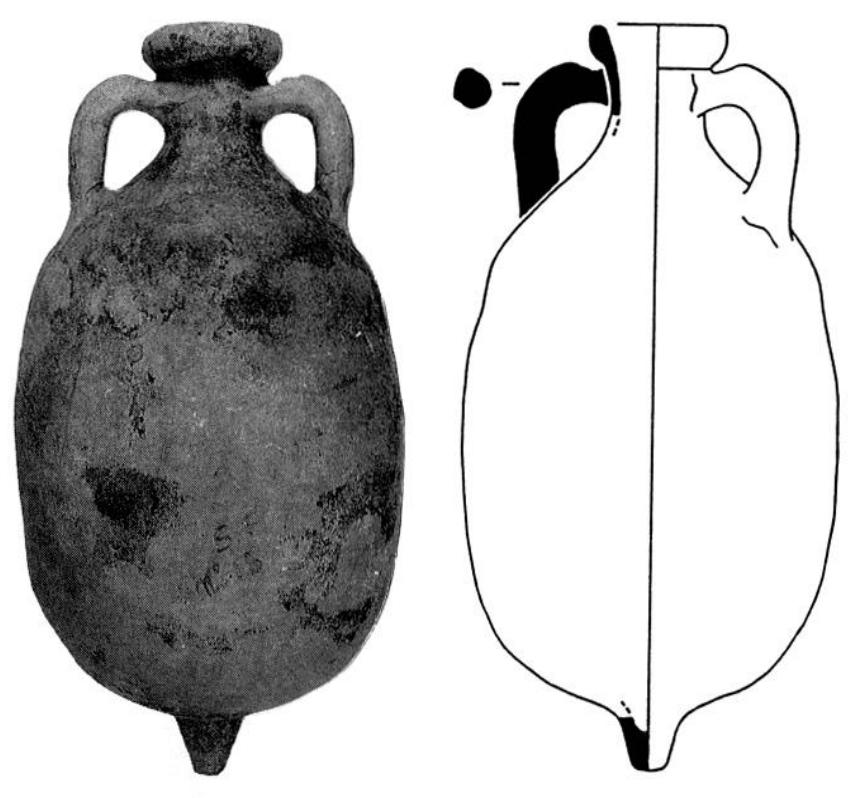

SF. 15
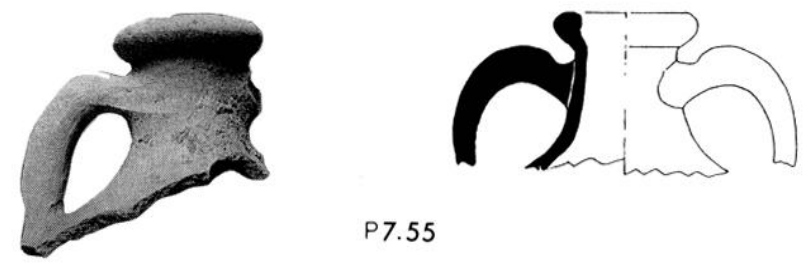

P7.55

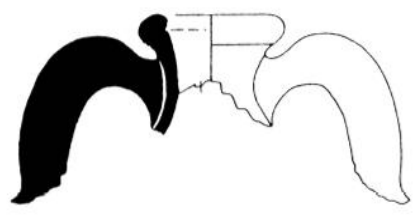

P13.19

Fig. 5-Amphores I)r. 20 des vides sanitaires de l'esplanade et du bassin. (F́chelle 1/10').

\section{Dressel 20}

Inv. SF. 15 : amphore complète (fig. 5), poids : $14 \mathrm{~kg}$, contenance : 36,81 , la forme est typique des productions du début du I'r s. (Martin-Kilcher, 1987, pl. 1).

\section{Amphores et cruches à fond plat}

Inn. SF. 01 : panse et col, départ d'anse à deux sillons, la lèvre manque (fig. 6), fond en cul de bouteille, pàte beige, fine. La légèreté de l'objet aux parois très peu épaisses suggère une cruche plutôt qu'une amphore.

In'. SF. 07 bis : haut et bas d'une cruche aux parois fines, plutôt qu une amphore; une partie de la panse manque (fig. 6), anse à un sillon, fond en cul de bouteille, pâte beige, fine.
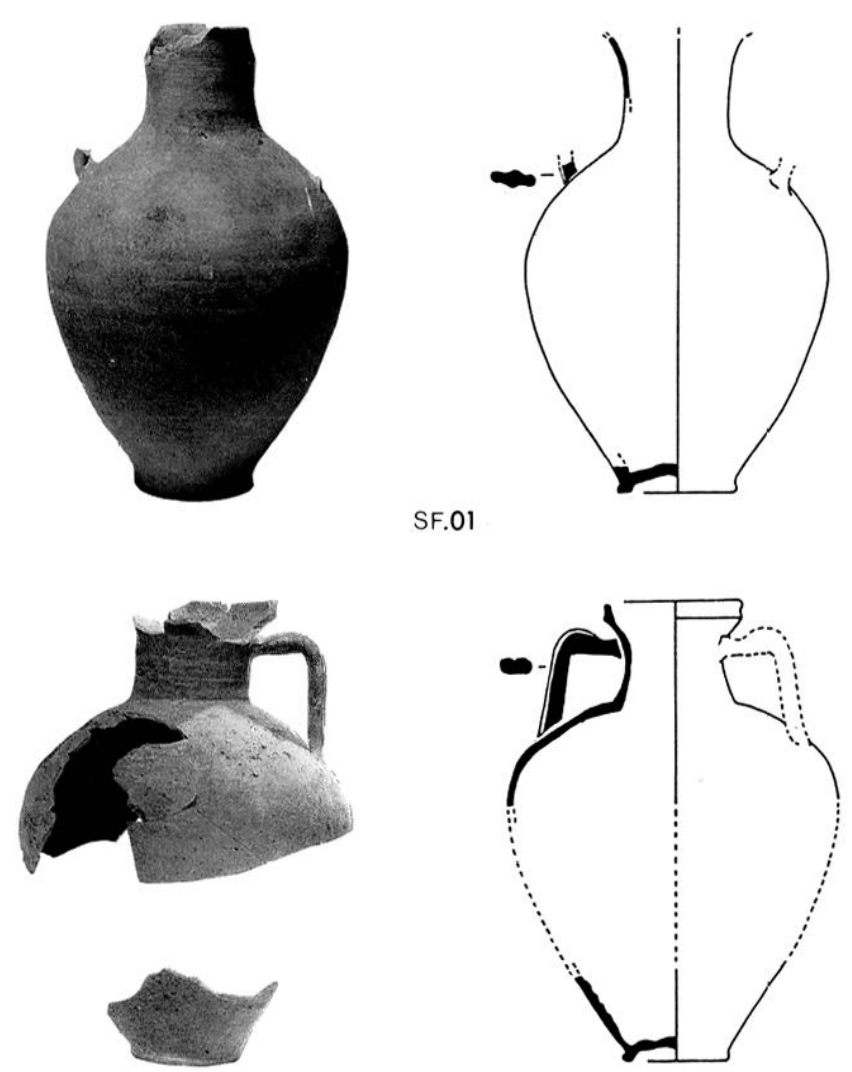

SF. 07 bis
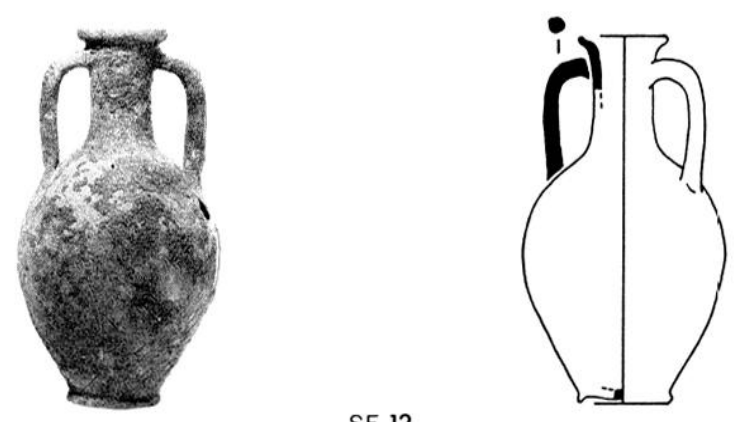

SF.12
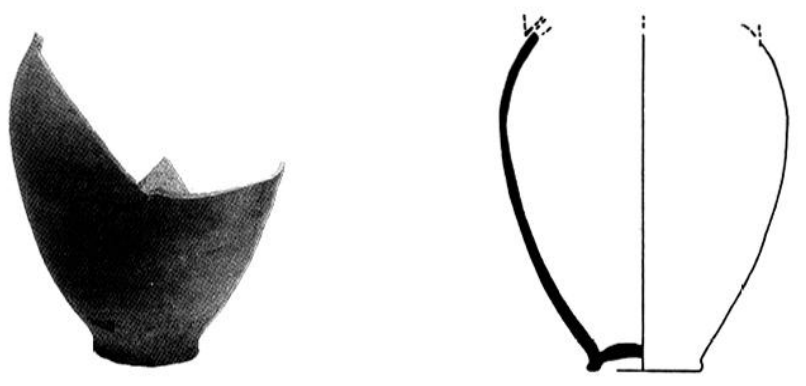

SF.13

Fig. 6 - Amphores ou cruches a fond plat du vide sanitaire de l'esplanade, sondage F. (Échelle 1/10").

Inv. SF. 09*: forme complète d'une amphore à fond plat, lèvre à double inflexion externe, anse à trois sillons (fig. 7). L'analyse de la pâte de cette amphore met en évidence son origine locale. 


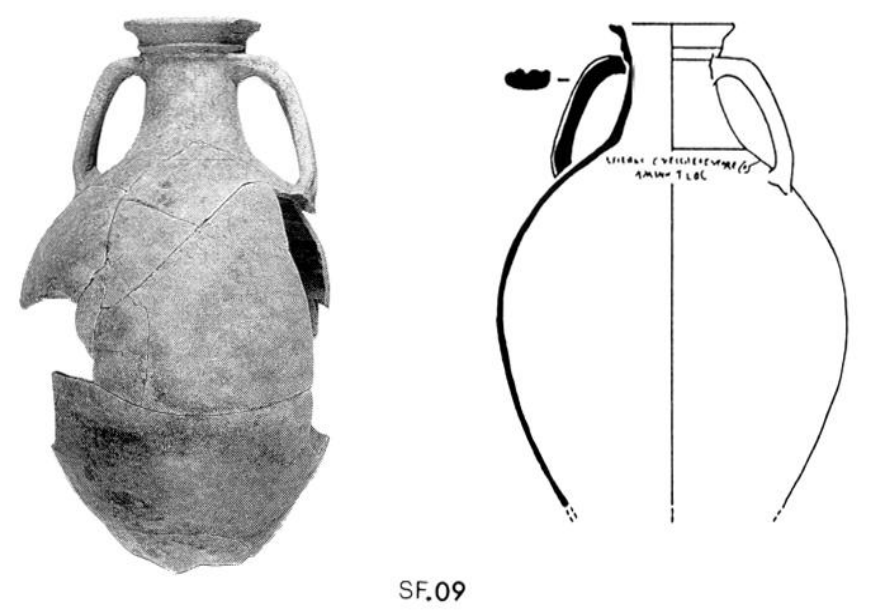

Fig. 7 - Amphores à fond plat et à lèvre à double inflexion externe (sondage $F$ ) avec marque peinte sur le haut de la panse. (Échelle 1/10").

Sa forme nest pas très éloignée de la Gauloise 7 . produite dans les ateliers d'Aspiran (IIérault) et de Velaux (Bouches-du-Rhòne) (Laubenheimer, 1985; Fontes et alii, 1981). J'avais attribué à la forme G. 7 un col identique à celui de notre amphore, trouvé également à Fréjus (Fontes et alii, 1981) et dont l'analyse physico-chimique atteste la provenance locale. La découverte d'une forme quasi complète à la Porte d'Orée et l'avancement des recherches dans ce domaine permettent désormais de modifier ce classement: le profil de la panse, dont le diamètre maximal est ici plus bas que sur les (G. 7, s'associe avec la lèvre à double inflexion externe, sans dépression interne, et à l'anse à trois sillons pour séparer les deux productions. Lamphore de Frejus s"inscrit dans les nombreuses variantes damphores à fond plat et lèvre à double inflexion externe, connues maintenant dans plus d'une dizaine dofficines du Haut-Empire en Gaule, notamment dans la région de Fréjus, à Cannes-Mandelieu ou à Cavalaire (Laubenheimer, 1989, p. 125-128). Il s'agit de productions variées qui ne visent pas à la standardisation que l'on a si bien su réussir avec les formes $\mathrm{G1}, \mathrm{G}, 4 \mathrm{ou}$ (i5. Elles n'en étaient pas moins destinées au commerce, comme le montre ici la marque peinte...
On lit, en effet, inscrit à l'encre noire sur le haut de panse: L(ucio) (Iunio) Silano, C(aio) Vellaeo Tutore co(n)s(ulibus) // Aminn(eum) T Loc (cf. infra, annexe III, p. 261). L amphore, datée par le nom des consuls du second semestre de l'année 28 après J.-C., contient du vin du cépage aminé, bien connu par ailleurs dans les amphores gauloises.

Inv. $S F .12$ : petite amphore ou cruche à deux anses, complète (fig. 6), hauteur : $34 \mathrm{~cm}$, volume : $3,9 \mathrm{l}$, anse cylindrique, pàte beige, fine. Elle est proche d'une amphore à fond plat produite, avec des Dr. 6A, dans un atelier de la région d'Aquilée, sous le Haut-Empire (Carre, 1985, p. 237 et fig. 9b) où, cependant, le module beaucoup plus important (hauteur : $60 \mathrm{~cm}$ ) a la capacité moyenne des amphores à fond plat ${ }^{3}$.

Inv. SF. 13 : panse et fond plat (fig. 6), pàte beige, fine.

Inv. SF. 14 : panse et fond anmulaire en cul de bouteille, pàte beige, fine.

\section{Amphores indéterminées}

Inv. SF. 04 : panse et fond pointu, pâte marronrouge, riche en inclusions, engobe jaunâtre.

Inv. $S F .05$ : panse et fond pointu, pâte orangée avec inclusions visibles.

Inv. $S F .06$ bis : fragment de col avec une partic de la lèvre et une anse cannelée, pàte beige, fine; trouvéc dans le col Dr. $2 / 4 n^{\circ} 6$.

Parmi les dix-huit individus (au minimum) découverts (tabl. I), les types représentés (Dr. 2/4, Dr. 7, Dr. 7/11 et [Or. 20) saccordent parfaitement avec la datation proposée par la stratigraphie: la date consulaire inscrite sur l'amphore à fond plat SF. 09 la confirme.

3 Elle est également proche des amphores de Foropopiliensi (Aldini, 1978), dont elle se distingue toutefois par le profil de la lèvre, de l'anse et du pied, comme par la taille.

Tableau I - I.es amphores du vide sanitaire de l'esplanade (nombre minimum d'individus).

\begin{tabular}{|l|c|c|c|c|c|c|c|}
\hline & Dr. 2/4 & Dr. 7 & Dr. $7 / 11$ & Dr. 20 & Autre & Fond plat & Total \\
\hline $\begin{array}{l}\text { Sondage F } \\
\text { Sondage D }\end{array}$ & 4 & 1 & 3 & 1 & 3 & 5 & 17 \\
\hline Total & 4 & 2 & 3 & 1 & 3 & 5 & 18 \\
\hline
\end{tabular}




\section{LE DRAINAGE DU BASSIN}

A l'est de l'esplanade, mordant sur le bassin, une extension est d'abord aménagée (P2), dont le soubassement était drainé simplement par du sable. Par la suite, une grande transformation (état II) change la fonction du secteur qui perd sa vocation maritime première (fig. 1). Le bassin du port est, en effet, comblé et l'on construit au-dessus un vaste bâtiment composé de plusieurs pièces (P10, P4, P5, $P 6)$ avec, au sud, un portique qui donne sur un espace ouvert, correspondant sans doute à un jardin. Il a été exploré en profondeur dans les zones P7 et P13. Sous des couches de remblai, un système de drainage sur lits d'amphores a été mis au jour. Il est disposé de part et d'autre d'une construction : un large plan incliné (M8ị, désaffecté et enterré (fig. 8).
En P7, sur $16,50 \mathrm{~m}^{2}$ et sur une profondeur de un mètre, 59 amphores au minimum, entières (27 ex.) ou fragmentaires (ce sont de gros morceaux, des hauts ou des bas entiers), ont été dégagées. Elles sont disposées sur deux niveaux au moins (fig. 9); la fouille a été interrompue par l'affleurement de la nappe phréatique, laissant des amphores en place. Postérieurement à la construction du mur 4 sur lequel elles viennent s'appuyer (fig. 10), les amphores sont placées en rangs serrés, inclinées du nord-ouest vers le sud-est, l'ouverture vers le haut ou vers le bas, sans systématique, parfois tête-bêche et parfois emboìtées partiellement. Il s'agit d'un ensemble assez homogène où les Dr. 2/4 d'une même famille de forme et de pâte constituent la majorité du lot (46 exemplaires sur 59). On compte aussi sept Pompéi VII, une Dr. 9, deux Dr. 20, un fond de G. 5 et

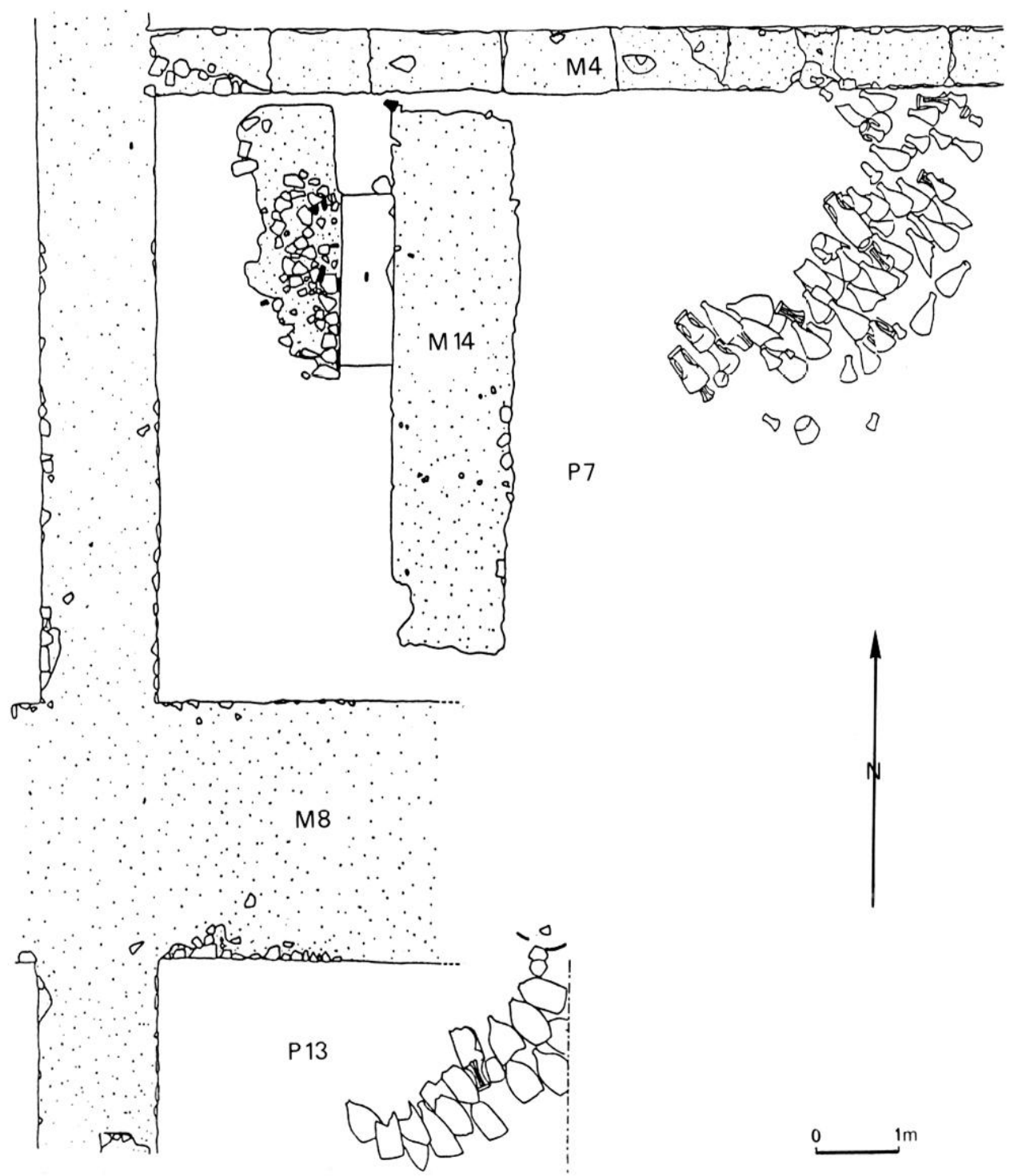

Fig. 8 -

Plan du vide sanitaire du bassin, zones P7 ef P13. 

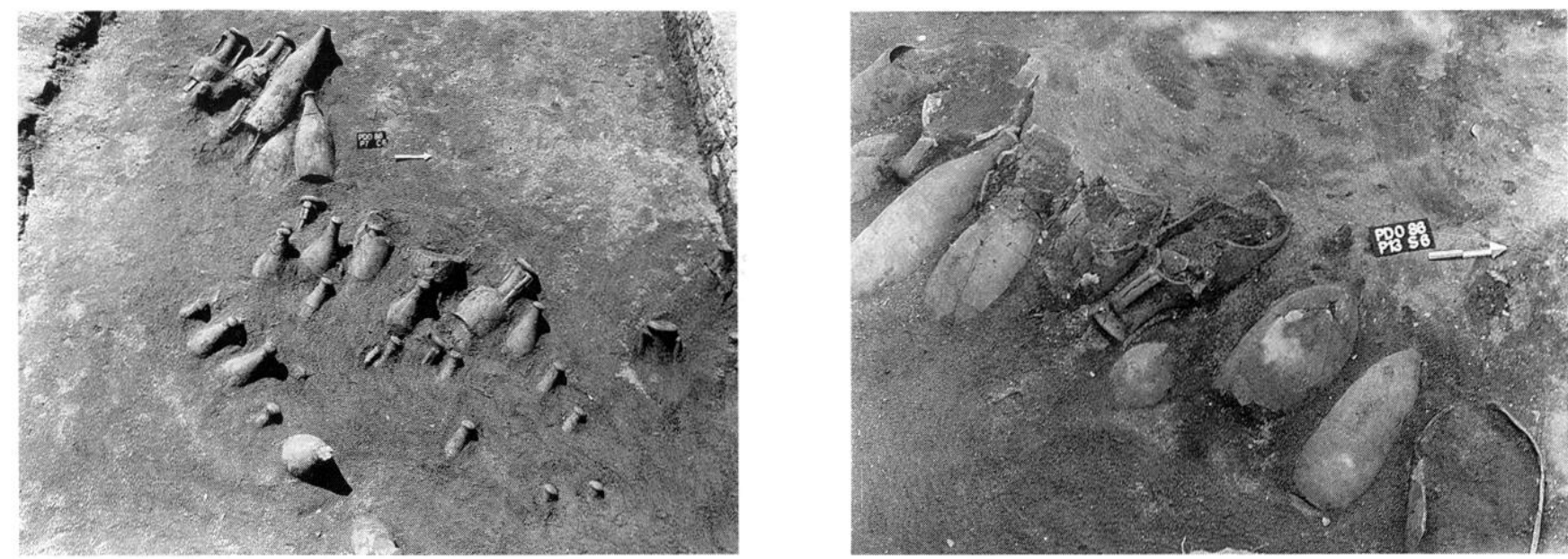

Fig. 9 - Vues du vide sanitaire du bassin, à gauche en P7; a droite en P13.

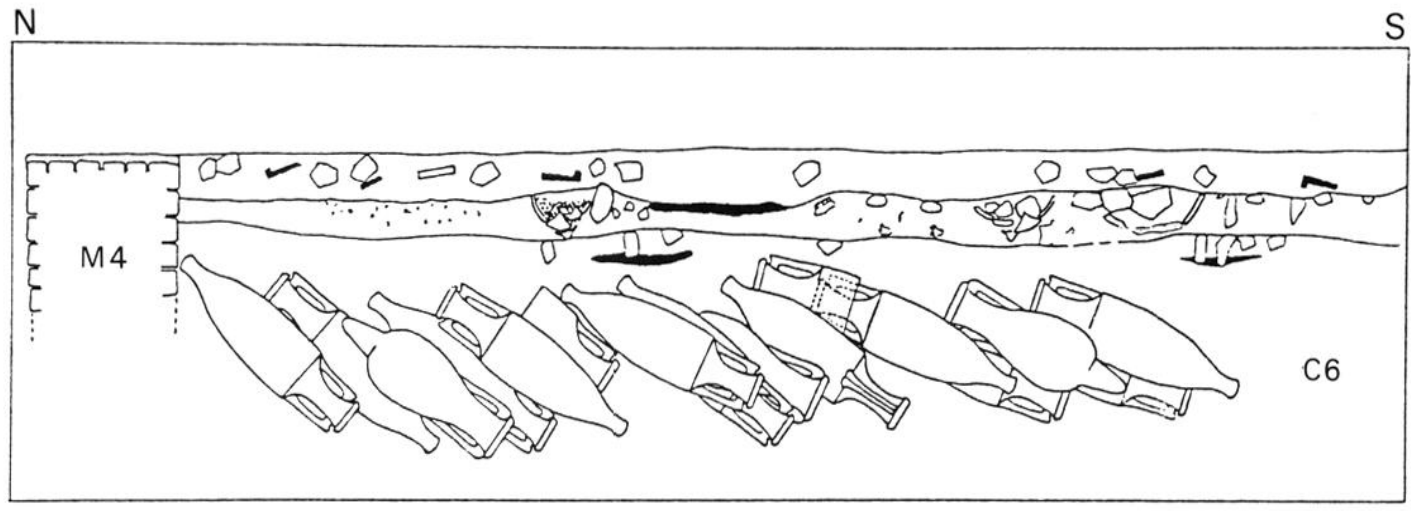

0

$1 \mathrm{~m}$

Fig. 10 -

Coupe du vide sanitaire du bassin en $P 7$. deux fonds indéterminés. Il ne semble pas y avoir de disposition organisee suivant la forme de ces divers objets.

Le mème dispositif est suivi en Pl3, où dix-sept amphores ont été dégagées sur $4,50 \mathrm{~m}^{2}$; le fond de la couche n'est pas atteint ici non plus. Il y a done un minimum de 3,5 amphores par mètre carré, soit une densité plus forte encore que sur l'esplanade. Inclinées selon la mème orientation qu'en P7, elles comptent une varièté de modèles plus grande: aux I)r. 2/4, I)r. 9, Pompéi VII et Dr. 20 s'ajoutent une Haltern 70, une Dr. T/11, une Ostia ISIX et une variante de la forme I)r. 14. Les [Or. 2/4 de forme et de pàte diverses constituent ici une majorité beaucoup moins forte (tabl. II).

Les amphores ont eté noyees dans une abondante couche de sable sur laquelle s'est établi le sol d'un jardin. Plusieurs arguments chronologiques fixent l'état II à l'époque flavienne, dans le dernier quart du $\mathrm{I}^{\mathrm{er}} \mathrm{s}$. de notre ere. Les types des amphores du vide sanitaire appartiennent globalement au I $^{\mathrm{er}}$ s. de notre ère et saccordent bien avec la datation proposée pour leur réutilisation.

Tableau II - Les amphores du vide sanitaire du bassin (nombre minimum dindividus).

\begin{tabular}{|c|c|c|c|c|c|c|c|c|c|c|c|c|}
\hline & Dr. $2 / 4$ & Dr. $14(?)$ & Н. 70 & G. 5 & Dr. 9 & P. VII & Dr. $7 / 11$ & Dr. 20 & O. LIX & Fond plat & Autre & Total \\
\hline $\begin{array}{l}\text { P7 } \\
\text { P13 }\end{array}$ & $\begin{array}{r}46 \\
7\end{array}$ & 1 & 1 & 1 & $\begin{array}{l}1 \\
2\end{array}$ & $\begin{array}{l}7 \\
1\end{array}$ & 1 & $\begin{array}{l}2 \\
2\end{array}$ & 1 & 1 & 2 & $\begin{array}{l}59 \\
17\end{array}$ \\
\hline Total & 53 & 1 & 1 & 1 & 3 & 8 & 1 & 4 & 1 & 1 & 1 & 76 \\
\hline
\end{tabular}




\section{Catalogue des amphores DU VIDE SANITAIRE DU BASSIN ${ }^{4}$}

Les références d'origine, signalées par un *, renvoient aux analyses de pâte par fluorescence $X$ qui sont présentées dans l'annexe I, p. 257.

\section{L'ENSEMBLE P7}

\section{Dressel $2 / 4$}

Toutes les Dr. 2/4 du vide sanitaire de la zone P7 ont la même pâte beige presque blanche, très cuite, riche en inclusions grises et blanches visibles à l'œil nu.

Inv. P7. 01 : haut de panse, col, lèvre et anses.

Inv. P7. 02: col avec anses et lèvre.

Inv. P\%. 03 : amphore entière reconstituée (fig. 11 et 12), poids : $19 \mathrm{~kg}$, contenance : $31,5 \mathrm{l}$.

Inv. P\%. 03A : haut de panse et col avec lèvre et anses.

Inv. P7. 04* : amphore entière reconstituée (fig. 11 et 12), poids : $19 \mathrm{~kg}$, contenance : $29,5 \mathrm{l}$. Origine : région de Fréjus.

Inv. P7. 04A : panse avec fond et départ de col.

Inv. P7. 05 : col avec lèvre, sans anse.

Inv. P7. 06 : fond.

Inv. P7. 07: haut du col lèvre et départ d'anses.

Inv. 17. 08 : amphore entière brisée.

Inv. P7. 09 : fond et haut brisés.

Inv. P7. 10* : amphore entière brisćc. Origine: région de Fréjus.

Inv. 17. 11 : fragments de panse, col et anses.

Inv. P\%. 12 : amphore entière brisée.

Inv. P7. $13:$ col avec lèvre et anses.

Inv. P7. 14 : panse avec fond et anses.

Inv. P7. 14A: col avec lèvre et départ d'anses.

Inv. P7. 15 : amphore entière reconstituée (fig. 11 et $12)$.

Inv. P7. 16 : amphore complète brisée.

Inv. P7.17* : amphore complète reconstituée (fig. 11 et 12 ), poids : $18 \mathrm{~kg}$, contenance : $29,5 \mathrm{l}$. Origine : région de Fréjus.

Inv. 17. 18* : amphore entière, sauf la lèvre et le haut des anses. Origine : région de Fréjus.

Inv. P7. 19 : amphore entière brisée.

Inv. P7. 20: col sans lèvre avec anses.

Inv. P7. 21 : amphore entière reconstituée (fig. 11 et

$12)$, poids : $18 \mathrm{~kg}$, contenance : $26,5 \mathrm{l}$.

Inv. P7. 22 : amphore entière brisée.
Inv. P7. $23:$ col avec lèvre et anse.

Inv. P7. 24 : amphore entière brisée.

Inv. P7. 25 : amphore entière brisée.

Inv. P7. 26 : col avec lèvre et départ d'anse.

Inv. P7. 27 : amphore entière sauf la lèvre.

Inv. P7. 28* : amphore entière reconstituée (fig. $11 \mathrm{et}$

12), poids: $14 \mathrm{~kg}$, contenance: $17,5 \mathrm{l}$. Origine: région de Fréjus.

Inv. P\%. 30 : amphore entière brisée.

Inv. P7. 31 : amphore entière brisée.

Inv. P7. 32 : amphore entière brisée.

Inv. P7. 33 : fond.

Inv. P7. 35 : fond.

Inv. P7. 36 : panse et fond.

Inv. P7. 37 : amphore entière brisée, poids : $20.8 \mathrm{~kg}$. Inv. P7. 38 : fond.

Inv. P7. 39 : amphore entière reconstituée (fig. 12), poids : $19,4 \mathrm{~kg}$, contenance : $31 \mathrm{l}$.

Inv. P7. 41 : amphore entière reconstituée (fig. 11 et 12), poids : $20 \mathrm{~kg}$, contenance : $25 \mathrm{l}$.

Inv. P7. 42 : col avec lèvre et anses.

Inv. P\%. 44 : fond.

Inv. P7. 45 : fond et panse avec une anse.

Inv. P\%. 46 : fond.

Inv. P7. 48 : panse et fond.

Inv. P7. 54 : fond.

Inv. P7. 56 : fond.

Inv. P7. 57 : amphore entière brisée.

Inv. P7. 59 : amphore entière brisée.

Inv. P7. 61 : fond.

Inv. P7. 63 : fond.

Inv. P7. 65 : panse brisée.

Inv. P7. F1: col sans lèvre, avec deux anses.

Inv. P7. F2bis : bas de panse et fond.

Inv. $\mathrm{P7} . \mathrm{F} 6$ : fond.

Inv. P7. $\mathrm{F} 8$ : fond.

Inv. P7. F11: col avec lèvre.

Inv. P7. F12 : fond.

Inv. P7. $F 15$ : lèvre.

Inv. P7. F16: lèvre.

Inv. P7. F17 : fond.

Inv. P7. F18: fond

\section{Gauloise 5}

Inv. P7. F3 : fragment de fond plat en forme de cul de bouteille caractéristique des $\mathbf{G} .5$ de l'atelier du Pauvadou à Fréjus, comme l'est aussi la pâte orangée, riche en inclusions.

\section{Dressel 9}

Inv. P\%. F13 : fragment de lèvre. 


\section{Pompéi VII}

Inv. P7. 40 : amphore entière, sauf une partie de la lèvre (fig. 13 et 14), pâte beige, poids : $20 \mathrm{~kg}$, contenance : $33,7 \mathrm{l}$.

Inv. P7. 43 : amphore entière (fig. 13,14 et 15), pâte beige, poids : $19 \mathrm{~kg}$, contenance : $32,7 \mathrm{I}$, un $\mathrm{P}$ tracé au doigt sur la pointe avant cuisson, la tête en bas. Inv. P7. 58: amphore entière (fig. 13 et 14), pâte beige, poids $21 \mathrm{~kg}$, contenance : $30,3 \mathrm{l}$.

Inv. P7. 60: amphore entière sauf un fragment de lèvre (fig. 13,14 et 15), pâte beige, poids : $19 \mathrm{~kg}$, contenance; $33,3 \mathrm{l}$, un $\mathrm{D}$ inscrit au doigt sur la pointe avant cuisson.

Inv. P7. 62: amphore entière (fig. 13 et 14), pâte beige, poids $21 \mathrm{~kg}$, contenance : $36,7 \mathrm{l}$.

Inv. P7. F2 : fond, pâte beige.

Inv. P7. F7 : fond, pâte beige.

\section{Dressel 20}

Inv. P7. 55 : col avec lèvre et une anse (fig. 5).

Inv. P7. F14: anse.

Inv. P\%. F19: anse et lèvre.

\section{Indéterminé}

Inv. P\%. F4: fond cylindrique, pâte beige, fine. Inv. P7. F5 : fond pointu, plein, pâte orangée, fine.

\section{L'ENSEMBLE P13}

\section{Dressel $2 / 4$}

Inv. P13. 01* : amphore entière, sauf le fond et une anse (fig. 16), anse bifide, pâte rouge orangé, riche en inclusions, blanches surtout, très visibles. Origine vraisemblable : Tarraconaise.

Inv. P13. 02*: amphore entière sauf la lèvre et le fond, anse faussement bifide avec un sillon externe et un sillon interne, un cercle au bas du col, pâte beige brun avec de grosses inclusions blanches (fig. 3). Origine incertaine.

Inv. P13. $05^{*}$ : amphore entière, sauf la pointe, anse faussement bifide avec un seul sillon externe, pâte brun rose, riche en inclusions blanches et grises (fig. 3). Origine incertaine.

Inv. P13. 11 : panse et fond, sans doute Dr. 2/4, pâte beige brun avec de grosses inclusions surtout blanches et grises, fines particules de micas.

Inv. P13. 14 : panse.

Inv. P13. 15* : panse avec naissance des anses et fond. Pâte rouge orangé, riche en inclusions blanches très visibles (fig. 16). Origine vraisemblable: Tarraconaise.
Inv. P13. 17* : amphore entière, sauf lèvre, une anse et fond, anse faussement bifide avec sillon interne et externe, pâte brun orangé avec inclusions blanches et grises (fig. 17 et 18). Sur le col, entre les anses, un timbre en creux dans un cartouche: MARI. La matrice est différente de celle de P13. 08. Origine : région de Fréjus.

Inv. P13. 02A : bas de panse, fond cassé.

Inv. P13. F19 : lèvre, pâte beige.

Inv. P13. F20*: col avec lèvre et départ des anses, pâte beige, presque blanche, riche en inclusions grises et blanches visibles à l'œil nu. Origine : région de Fréjus.

\section{Dressel 14, Haltern 70 ou Pascual 1 ?}

Inv. P13.08* : amphore entière, sauf la pointe, anse à un sillon, la lèvre n'est pas soulignée autrement que par une inflexion externe, un cercle à l'attache du pied à la panse (fig. 17 et 18). Contenance : $21,5 \mathrm{l}$. C'est une forme un peu bâtarde entre Dr. 14 et Haltern 70, voire Pascual 1. Le pied ne présente pas, à l'intérieur, la protubérance en forme de boule caractéristique des productions de Bétique. Nous nommerons cette amphore Dr. 14 (?) dans la suite du texte. Pâte brun orangé, avec inclusions blanches et grises. Sur le col, entre les anses, un timbre en creux dans un cartouche : MARI, la matrice est différente de celle de P13. 17 sur Dr. 2/4. Origine : région de Fréjus.

\section{Haltern 70}

Inv. P13. 18: amphore entière, sans lèvre, manque une anse, anse à un sillon, fond plein; forme et pàte sont caractéristiques de la production de Bétique (fig. 19).

\section{Dressel 9}

Inv. P13. 06 : amphore entière, sauf une anse, anse sans sillon, poids : 16,5 kg, contenance : $26,6 \mathrm{l}$ (fig. 20).

Inv. P13. 16 : amphore entière sauf la lèvre, anse à deux sillons, poids restitué : $17 \mathrm{~kg}$, un $\mathrm{R}$ tracé au doigt sur la pointe (fig. 15 et 20 ).

\section{Pompéi VII}

Inv. P13. F16 : haut du col, lèvre et départ d'anses (fig. 13 et 14).

\section{Dressel $7 / 11$}

Inv. P13. 03 : panse, col et anses fragmentaires. 

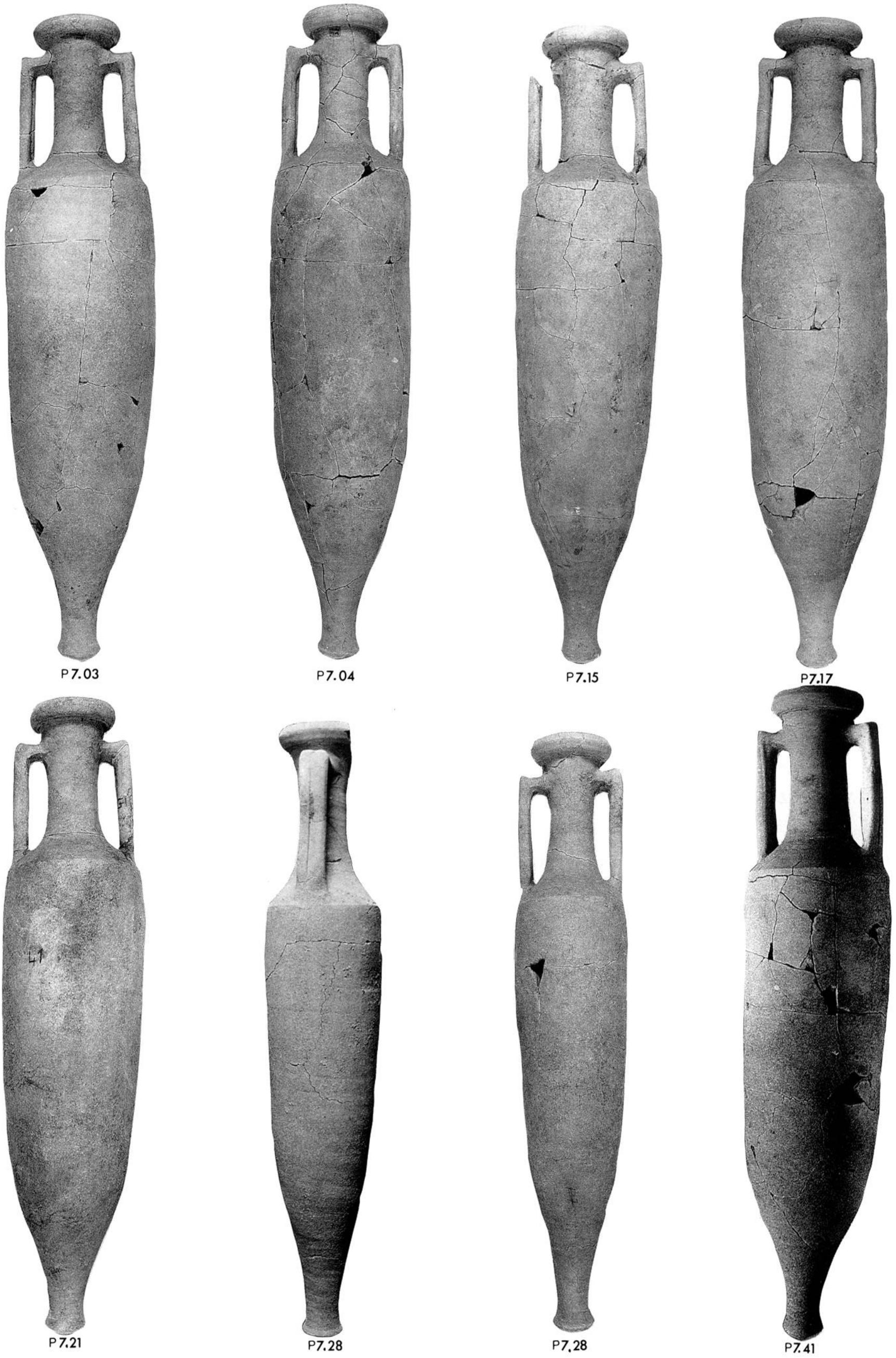

Fig. 11 - Amphores Dr. 2/4 fabriquées dans la région de Fréjus. (Échelle 1/10). 


$$
\int_{1}^{-1} \int_{1}^{-1} \int^{1}
$$




$$
149
$$



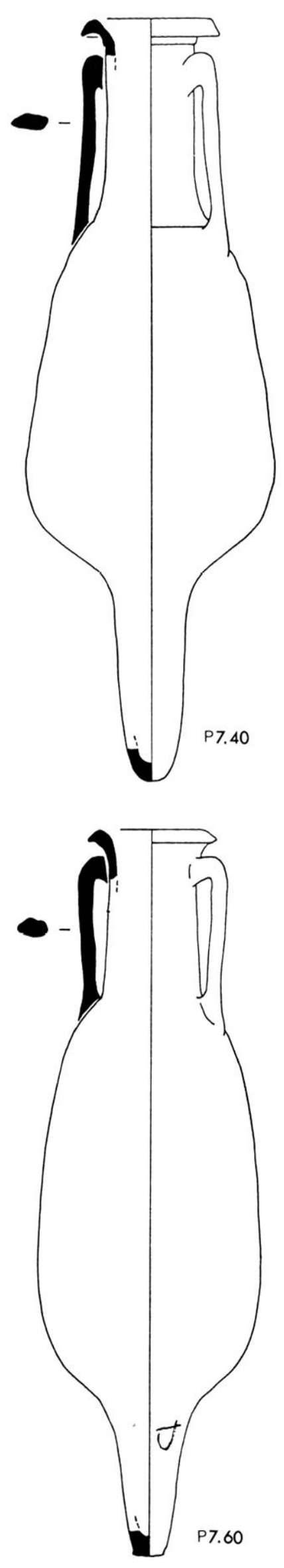
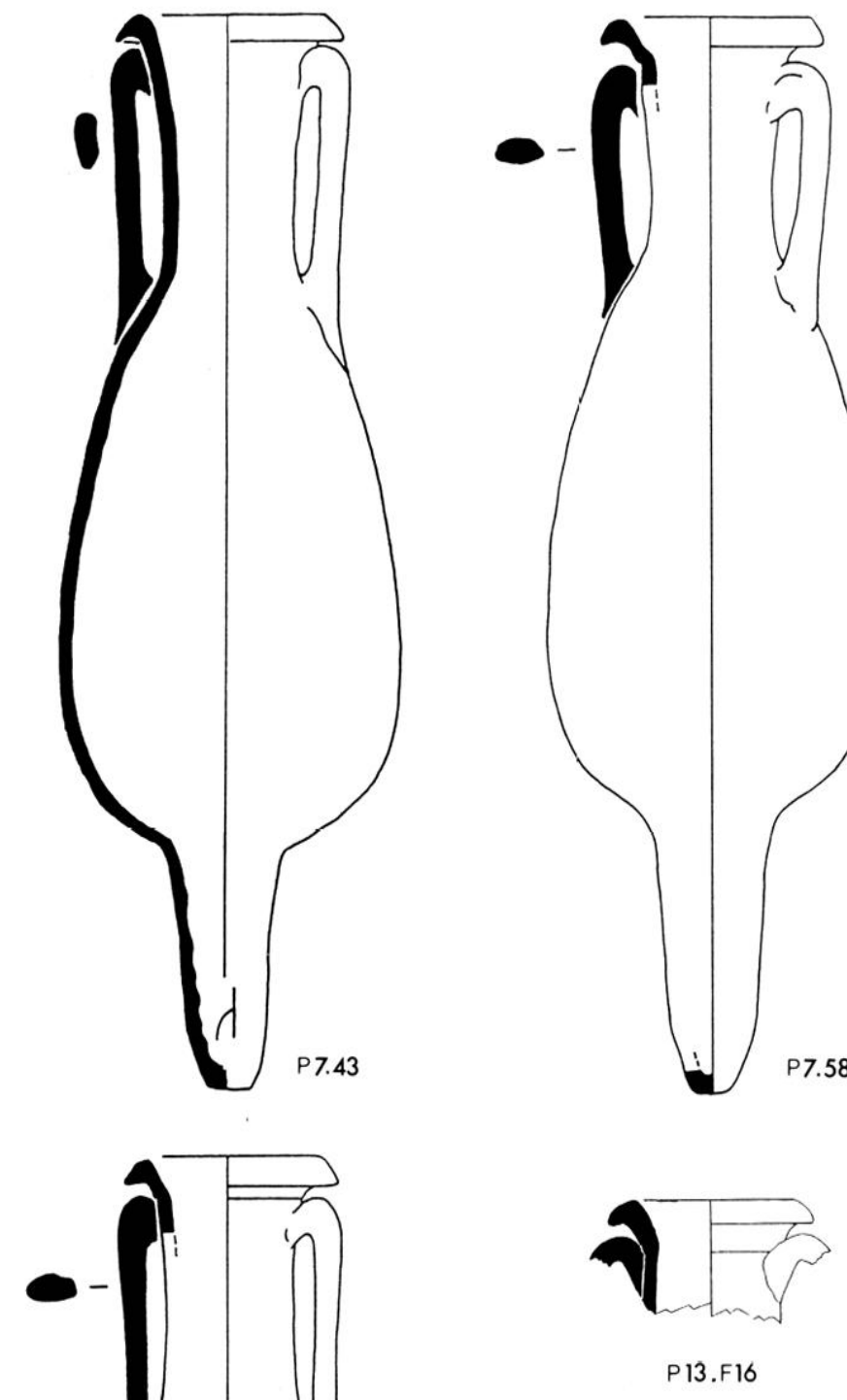

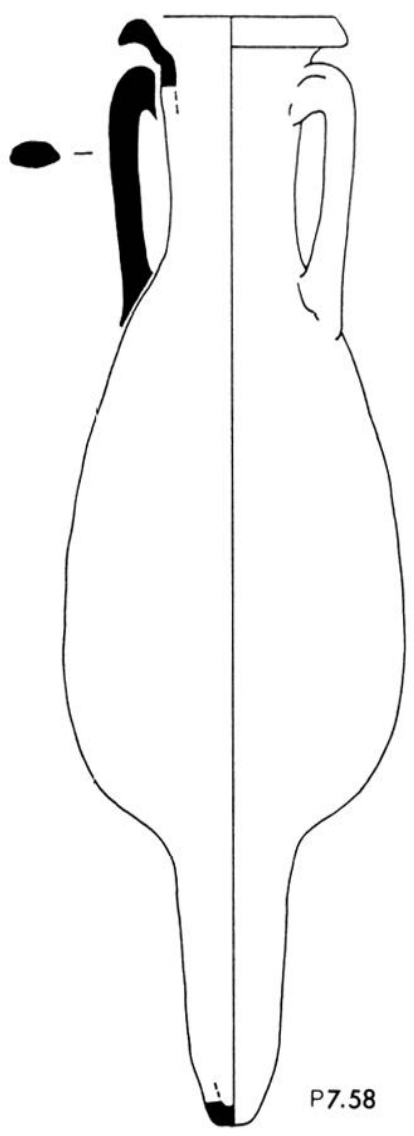

Fig. 14 - Amphores Pompéi VII du vide sanitaire du bassin en P7 et P13. (Échelle $1 / 10^{\circ}$ ). 


$$
\begin{array}{ll}
D & \\
R &
\end{array}
$$



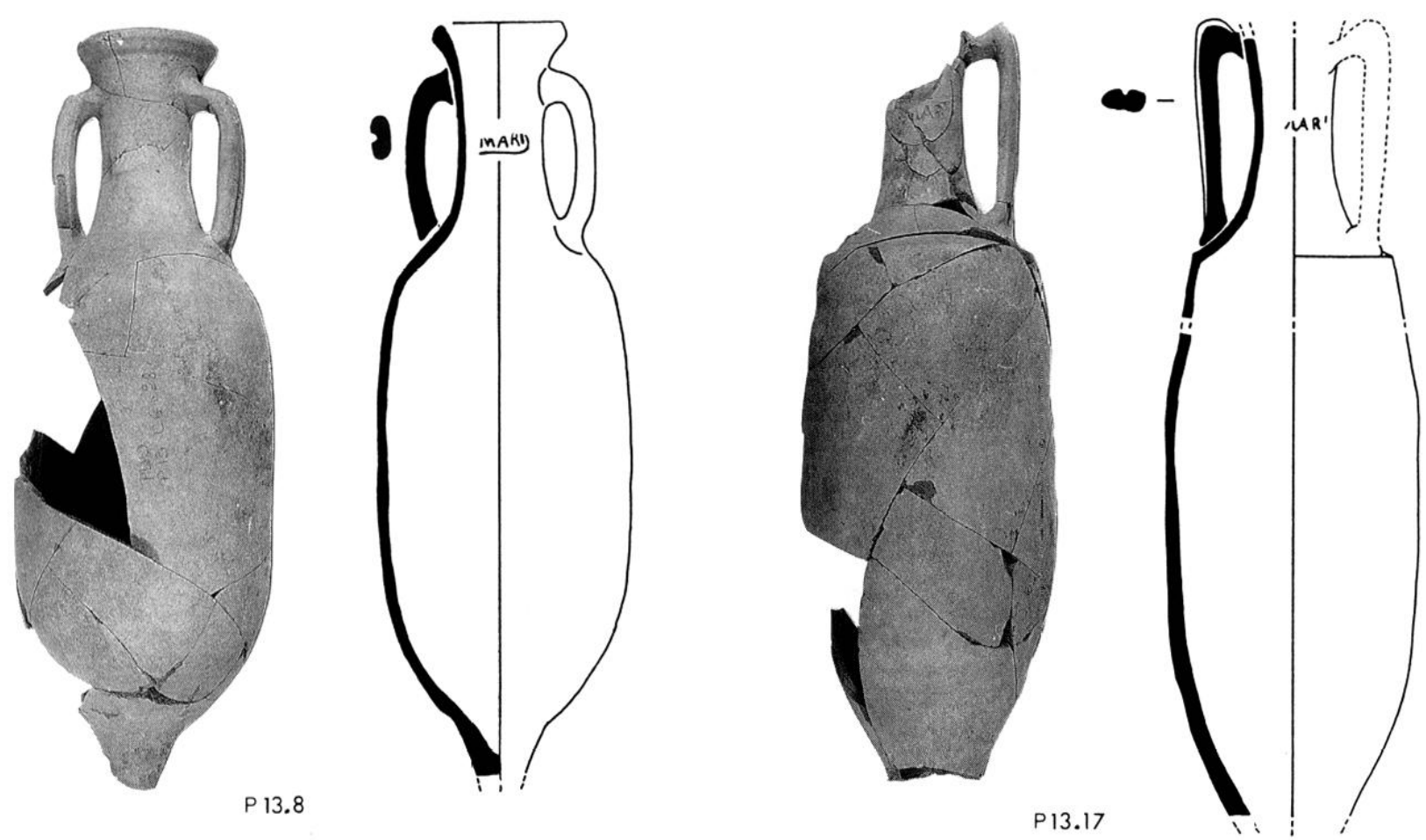

lïg. 17 - Amphores fabriquées dans la région de Fréjus et timbrées MARI. A gauche, Dr. 14?; à droite, Dr. 2/4. (Échelle 1/10").

\section{Dressel 20}

Inv. P13. 19 : haut du col, lèvre et une anse, le profil de la lèvre est caractéristique de l'époque flavienne (fig. 5).

Inv. P13. F17: anse.

Inv. P13. F18: anse.

\section{Ostia LIX}

Inv. P13. 12 : amphore entière sauf la pointe, panse cylindrique, lèvre arrondie, anse ronde, fond creux, pâte beige à l'extérieur, rosée à l'intérieur, très chargée en inclusions sableuses blanches et chamote. Un bouchon circulaire a été découpé dans le haut de la panse (fig. 19). Cette amphore, rare en Gaule, est connue dans les niveaux flaviens et au début du ${ }^{\mathrm{e}}{ }^{\mathrm{e}} \mathrm{s}$. dans les fouilles des Thermes du Nageur à Ostie (Panella, 1973, p. 571) et également à Pompéi; on ne sait encore avec certitude ni son lieu de production, ni son contenu. La forme générale de l'objet et les exemplaires découverts en Algérie orienteraient les recherches vers l'Afrique.

\section{Forme non identifiée}

Inv. P13. 07*: lèvre, pâte beige avec inclusions visibles. Son origine ne se situe pas dans la région de Fréjus.

\section{Cruche ou amphore à fond plat}

Inv. P13. 01A : fond plat, pâte beige.

La partie fouillée du vide sanitaire $d u$ bassin contient un minimum de 76 amphores dont 59 appartiennent à la zone P7, la plus largement fouillée (tabl. II). Tout porte à croire que l'aménagement. du système de drainage a été réalisé d'un seul élan. En P7 et en P13, on utilise en majorité les mêmes formes d'amphores : Dr. 2/4, Dr. 9, Pompéi VII ou Dr. 20. Quelques types marginaux se répartissent dans l'une ou l'autre zone: Dr. 14 (?), H. 70, Gauloises, Ostia LIX ... rien d'étonnant dans un échantillonnage de fouille limité. Une différence intéresse cependant les Dr. $2 j 4$ : on a regroupé en P7 un lot homogène de 47 objets de la même pâte blanche, très cuite, voire trop, tandis qu'en P13, les Dr. 2/4, moins nombreuses, comptent des formes et des pâtes variées, avec un seul col (P13. F20) qui a le mème aspect et la même origine que le lot des amphores de la zone P7.

Le drainage du bassin est mis en place quelques dizaines d'années sans doute après celui de la terrasse. Les amphores choisies pour ces deux opérations accusent certaines différences si l'on s'en tient à l'échantillonnage modeste et sans doute insuffisant de la première. 

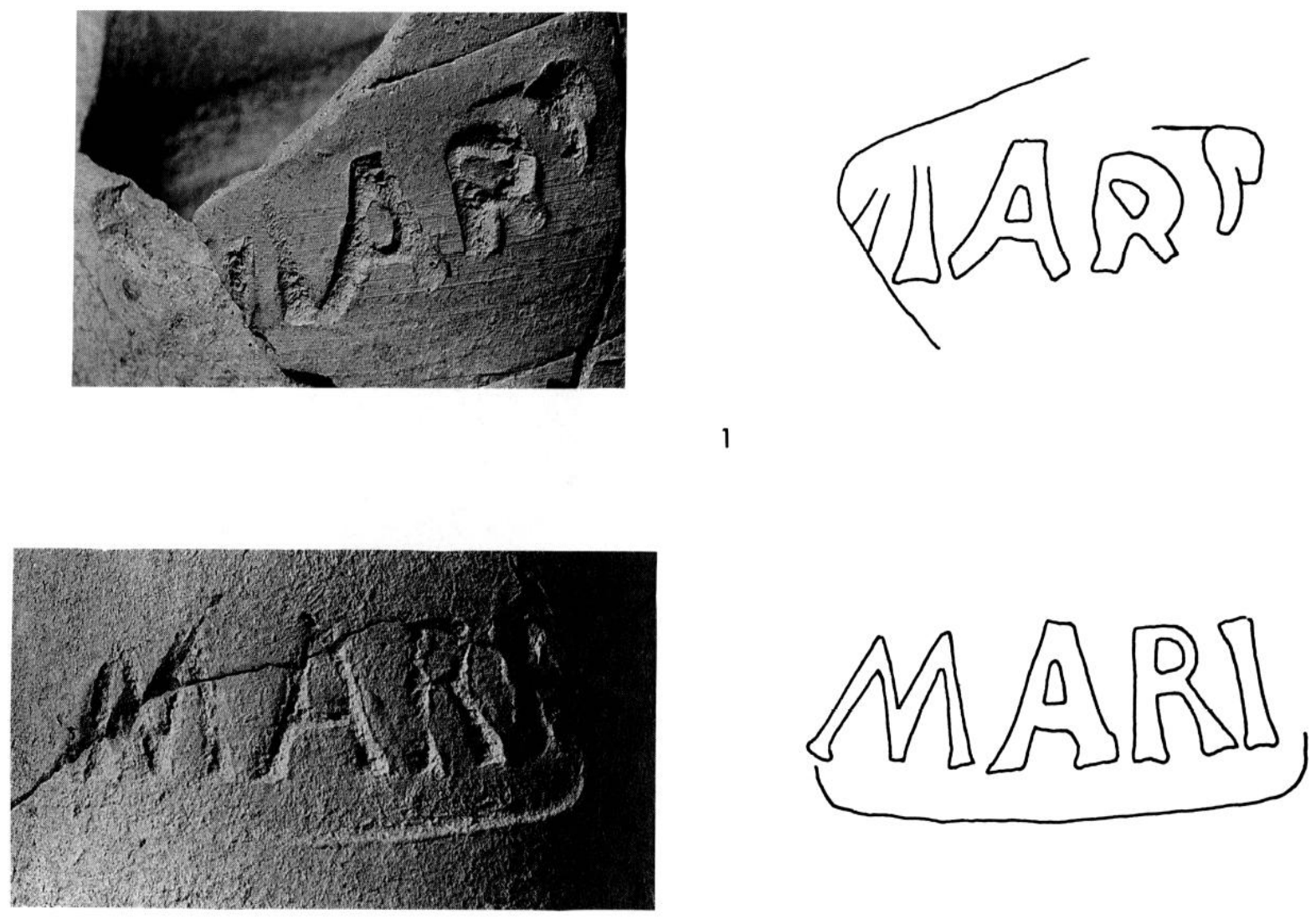

2
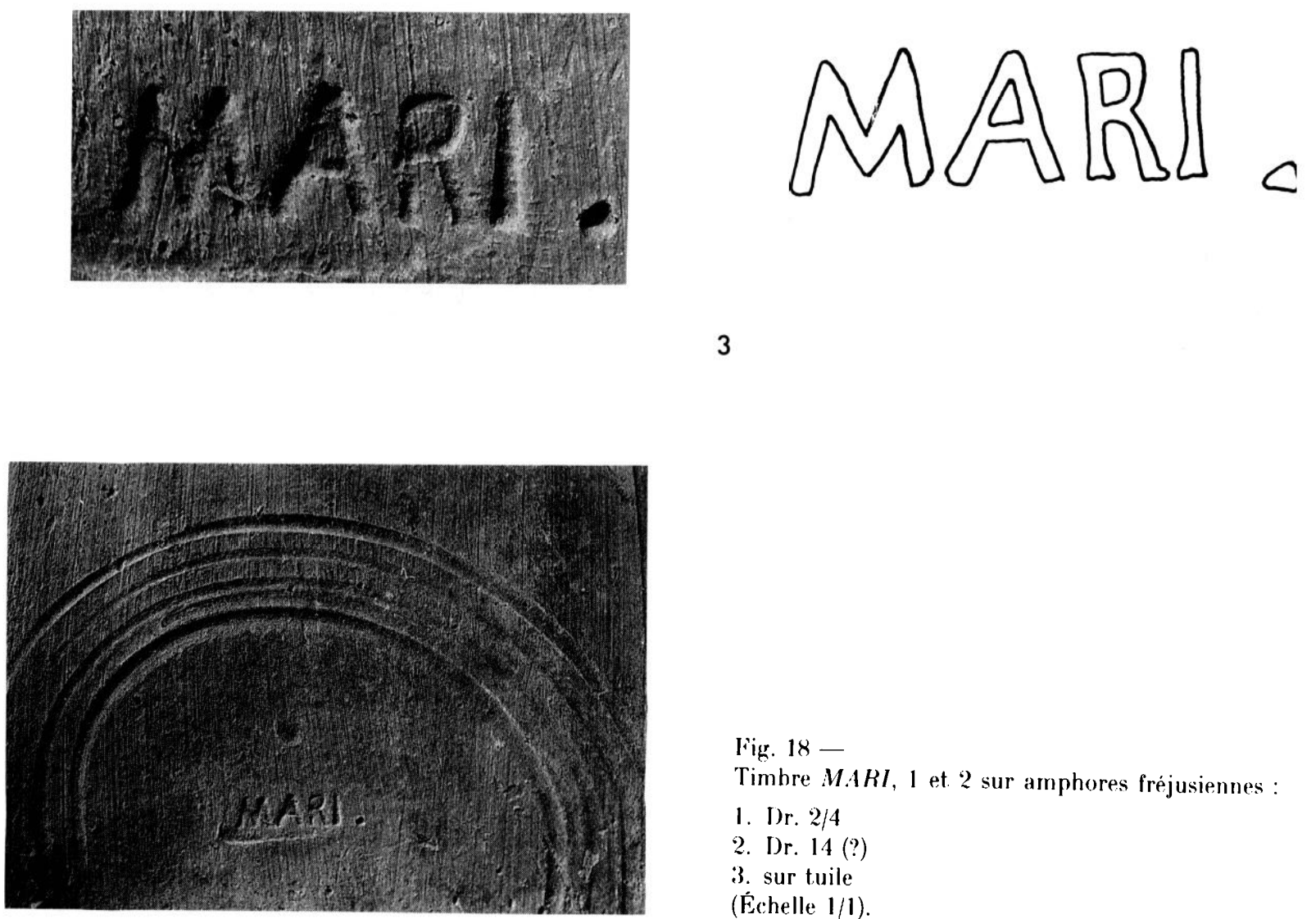

Fig. $18-$

Timbre $M A R I, 1$ et 2 sur amphores fréjusiennes :

1. Dr. $2 / 4$

2. Dr. $14(?)$

3. sur tuile

(Échelle 1/1). 

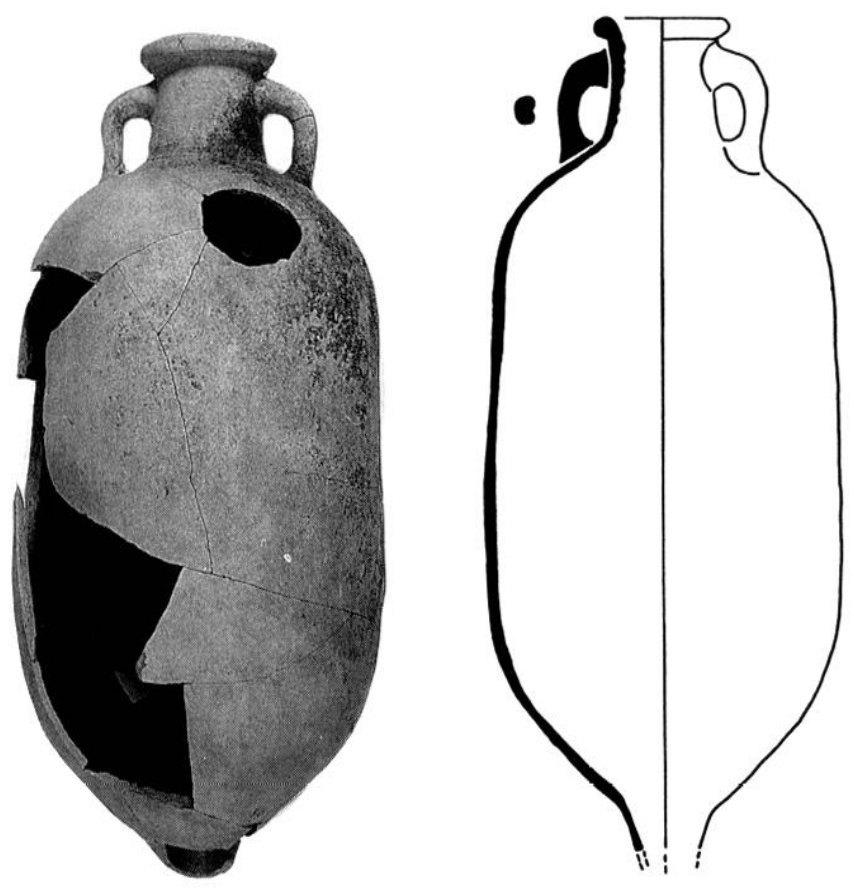

P13.12
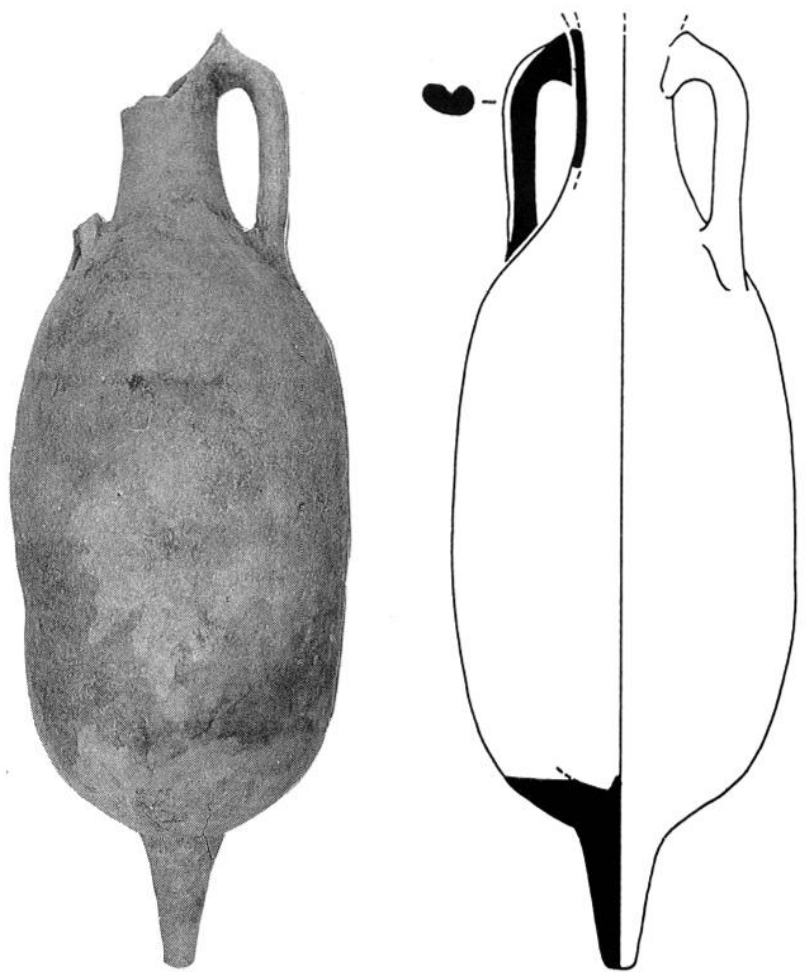

P 13.18

Fig. 19 -- Amphores du vide sanitaire du bassin (P13). A gauche, Ostia LIX; a droite, Haltern 70. (Ëchelle 1/10").

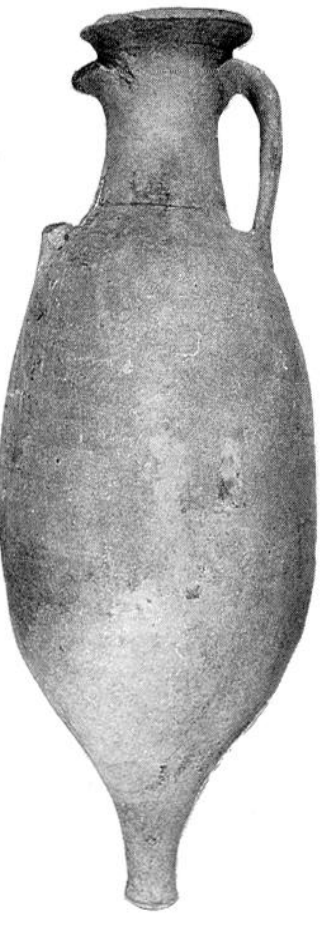

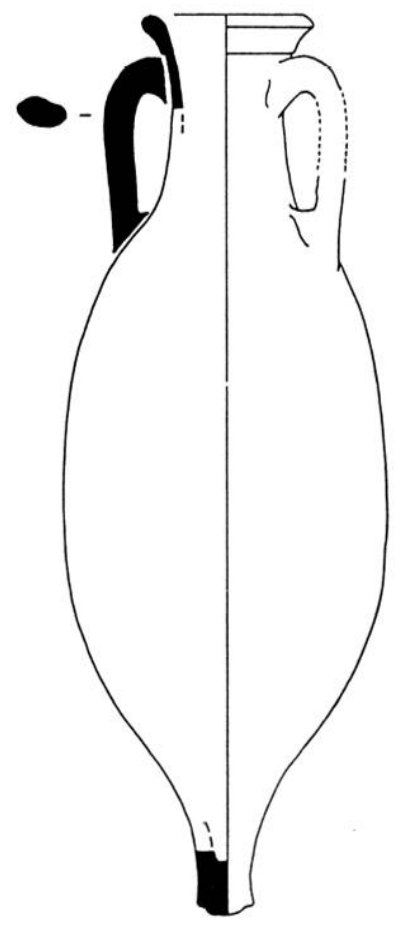

P 13.6
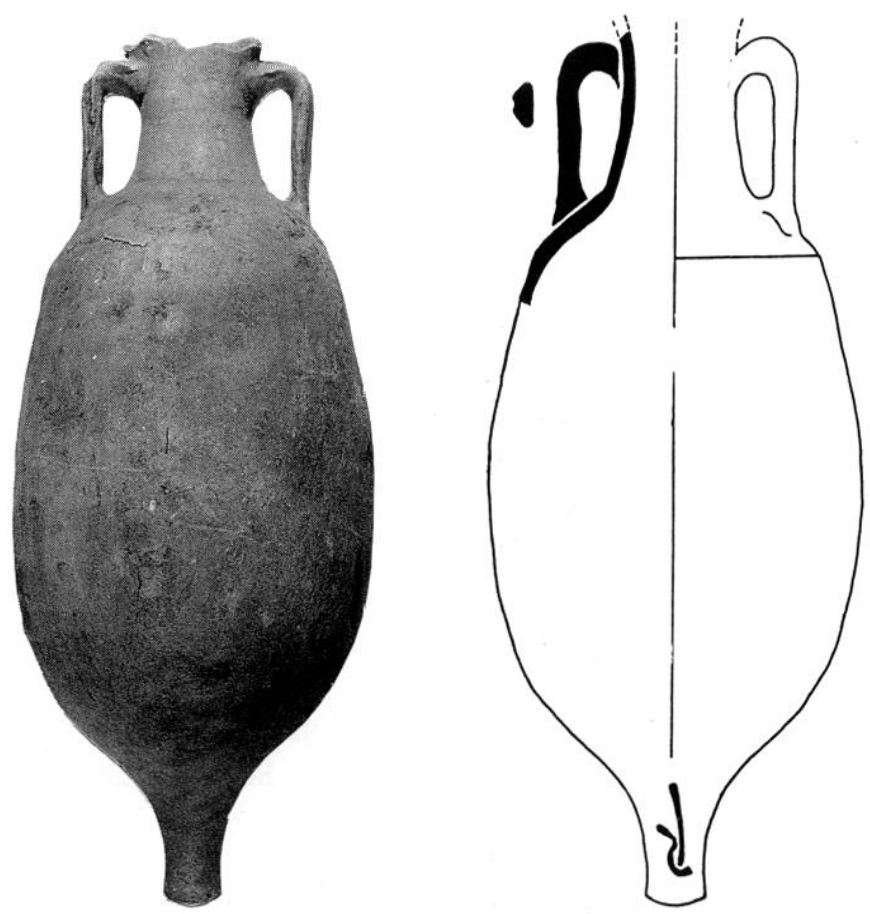

P 13.16

Fig. 20 - Amphores Dr. 9 dans le vide sanitaire du bassin. en Pli3. (Ëchelle 1/10"). 
Pour les Dr. 2/4, il y a, dans les deux cas, des importations de Tarraconaise, mais seule, la pompéienne est réutilisée dans les années 30; en revanche, le groupe très important des amphores à pâte blanche et panse étroite, qui se révèlent ètre fréjusiennes, n'apparaît qu'à l'époque flavienne, comme, au reste, l'autre modèle timbré $M A R I$. C'est à cette période aussi qu'on trouve l'unique G. 5 locale, en accord avec la chronologie de la production de l'atelier du Pauvadou à Fréjus, durant la seconde moitié du I $^{\mathrm{er}} \mathrm{s}$. (Brentchaloff, 1980 ; Laubenheimer, 1985). En revanche, et pour la première fois, on peut attester à Fréjus la production d'amphores à fond plat et lèvre à double inflexion externe dès l'époque de Tibère, comme l'indique la date consulaire de l'exemplaire du drainage de l'esplanade.

Les Dr. 20, dont la panse sphérique s'adapte mal aux formes allongées de la plupart des amphores choisies ici, sont peu nombreuses. L'exemplaire entier de la terrasse est caractéristique d'un modèle augustéen, tandis que les profils des cols trouvés dans le bassin correspondent à l'évolution de la production dans les années 50-70 de notre ère (MartinKilcher, 1987, fig. 28 et pl. 1).

On ne s'étonnera pas de voir réutilisées sous les Flaviens les formes Dr. 9, H. 70 et Pompéi VII qui auraient pu tout aussi bien appartenir déjà au vide sanitaire de la terrasse.

\section{SPÉCIFICITÉ DU SYSTÈME DE DRAINAGE?}

Dans le quartier de la Porte d'Orée où l'ensemble des constructions nécessitait un assainissement, on a utilisé dans les pièces 5 et 6 un autre système constitué de déchets de taille de pierres recouverts de sable (cf. supra, p. 182). Le remploi des amphores était peut-être réservé aux parties extérieures que sont l'esplanade et le jardin. Toujours à Fréjus, dans le quartier des Aiguières, au cours des premières décennies de notre ère, des Haltern 70 drainent une rue : couchées horizontalement et emboîtées les unes dans les autres, elles forment deux lignes parallèles (Goudineau, $1981 ; 1982)$.

Le drainage par les amphores est, en réalité, un procédé ancien dont on découvre peu à peu la multiplicité et la variété des applications. Comme on le voit à Fréjus, les amphores servent à la fois pour des drains et pour des vides sanitaires.

Les drains sont de longs tuyaux vides, constitués d'amphores entières, emboîtées horizontalement les unes dans les autres, comme c'est le cas aux Aiguières. On trouvera un autre exemple dans le système d'assainissement du terrain marécageux de Ia
Longarina, à Ostie, aménagé sous Auguste : il comptait environ 360 amphores allongées sur le sol, formant de longues files parallèles de deux ou trois amphores de front (Hesnard, 1980).

Les vides sanitaires, plus ponctuels, s'inscrivent sous les pièces d'une maison ou sous des cours, voire sous ou le long des murs : on creuse une vaste excavation pour la combler par des amphores, généralement noyées dans du sable ou du gravier. La position des amphores, leur qualite, comme le nombre de niveaux sur lequel elles s'empilent, varient. Le bel exemple de Rhodes, au $111^{\mathrm{e}} \mathrm{s}$. avant notre ère, montre des dizaines d'amphores juxtaposées, la pointe en l'air sur deux niveaux superposés (Grace, 1979, fig. 63).

En Gaule, la réutilisation des amphores dans l'aménagement des sols se pratique de longue date et sous diverses formes.

A Lattes (Hérault) un site particulièrement touché par les problèmes d'humidité, dès le $v^{e}$ s. avant notre ère, on pave les sols de tessons d'amphores étrusques et surtout massaliètes (Py, 1988), que l'on dépose, parfois, sur un lit de sable (Roux, Verdier, 1989).

A Marseille, on peut penser que les amphores massaliètes entières (plus d'une centaine), placées horizontalement sur deux couches, dans le remblaiement artificiel aménagé sous le bassin d'eau douce du port, servaient de drainage (Salviat, 1972).

A la fin du $I^{\mathrm{e}} \mathrm{s}$. et au $\mathrm{I}^{\mathrm{er}} \mathrm{s}$. avant notre ère, le remploi d'amphores (gréco-italiques ou Dr. 1) pour assainir se multiplie. Ce sont ces extraordinaires cabanes de torchis de Châteaumeillant (Cher) assises sur un vide sanitaire où les amphores, souvent réduites à leur panse, sont disposées côte à côte, verticalement, tantôt la pointe vers le haut et tantôt le col (Picard, 1959). De mème à Toulouse, des habilats semi-enterrés se protègent de l'humidité par un lit d'amphores Dr. 1, posées horizontalement et recouvertes d'une couche de brûlis (Müller, 1981). A Arles (Sainte-Luce), où les problèmes de remontée d'eau sont fréquents le long du fleuve, le drainage se fait par des panses d'amphores Dr. 1 dressées verticalement et juxtaposées (Jacob el alii, 1987-1988, p. 231); dans le cimetière de Trinquetaille, une vaste esplanade bordée d'un portique est drainée par des Dr. 1 placées en lignes, verticalement (communication de J.-M. Rouquette; Euzennat, 1969). A la même époque, les constructions établies au pied de l'oppidum de Montfo à Magalas (Hérault) s'accompagnent de divers systèmes d'assainissement: ici, une rangée de Dr. 1 ou de gréco-italiques verticales calées par des pierres et surmontées de quatre 
rangées d'amphores horizontales; là, une banquette de pierres se fonde sur une ligne de panses verticales: ailleurs encore, on a disposé, à la base d'un mur, une rangée de panses horizontales, placées tête-bèche (Bacou, 1982-1983).

Les problèmes d'humidité ne sont pas étrangers à Vitruve (Arch., V, 9) qui propose une technique de drains pour les lieux découverts : «afin que les allées soient toujours exemptes d'humidité, il faut creuser et vider le terrain bien profondément, et bâtir à droite et à gauche des égouts dans lesquels il y ait des drains qui descendent des deux côtés des allées. Après avoir empli ces drains de charbon, il faut $y$ mettre du sable par dessus et dresser l'allée, qui, à cause de la rareté naturelle du charbon, sera exempte d'humidité parce que les conduits l'épuiseront en la déchargeant dans les égouts" (traduction C. Perrault). Il indique d'autre part (Arch., VII, 4) un système analogue, à base de charbon et de sable, pour isoler le sol des pièces, mais, à aucun moment, il ne préconise l'utilisation d'amphores vides.

Pourtant, la Gaule du Haut-Empire, comme l'Italie, voient se multiplier la pratique des vides sanitaires sur lits d'amphores. C'est dans la région de Lyon et de Vienne, sur les bords humides du Rhône, que les exemples sont les plus nombreux. Dès la fin du $\mathrm{XIX}^{\mathrm{r}}$ s., Allmer et I)issard soulignent les nombreuses découvertes faites à Lyon, Sainte-Colombe et Vienne (Allmer, Dissard, 1887-1888). "On a découvert plusieurs fois, de considérables accumulations de vases qui ont permis de reconnaître qu'en dehors des usages domestiques, ils ètaient employés dans les substructions des édifices comme matière à remblai et, en même temps, comme moyen préservatif contre l'humidité. A cet effet, l'on choisissait de préférence les amphores dont la forme est presque entièrement sphérique (ce sont des Dr. 20), et on les déposait l'ouverture en bas, par lits superposés alternant avec des couches de sable" (Allmer, s.d., p. 187). Depuis lors, d'autres découvertes peuvent être signalées : plusieurs centaines de Dr. 20 à Sainte-Colombe-lesVienne où elles sont régulièrement placées verticales, sur la lèvre, la pointe en haut (Revue Épigraphique, 1902, no 1479), sur un, deux ou même trois niveaux superposés (Helly, Le Bot-Helly, Liou, 1986); mème disposition à Lyon au quartier de La Solitude, sur deux niveaux (Bruhl, 1964), ou à Saint-Just où d'autres formes se mêlent aux Dr. 20 sur un seul niveau (Reynaud, Lasfargues, Desbat, 1973), comme rue de Ia Favorite (Becker et alii, 1986). Parfois encore, des amphores de forme allongée sont posées horizontalement sur les Dr. 20 verticales (Vassy, 1914). Mais les aménagements les plus spectaculaires se trouvent à Lyon sous la place Bellecour où le creusement d'un parking, en 1966, a entrainé la destruction de milliers d'amphores (Becker et alii, 1986) et à Vienne sous les grands horrea draînés, sur toute leur surface, par quatre a cinq mille amphores Dr. 20 (Becker et alii, 1986).

Le procédé d'assainissement mis en cuvre à Fréjus au $\mathrm{I}^{\mathrm{er}} \mathrm{s}$. s'inscrit donc dans une tradition ancienne et bien développée en Gaule qui se poursuivra encore dans le temps (par exemple à Carpentras ou à Nîmes au $111^{\mathrm{e}}$ s., Laubenheimer, 1985, p. 58 , note 33). Le nombre imposant des amphores que nous présumons avoir été mobilisées est en somme assez banal et correspond à la norme dans ce type de construction qui rassemble les objets par centaines et par milliers. Si, le plus souvent, dans la région lyonnaise, on utilise des amphores de la même forme, des Dr. 20, la diversité des types rassemblés à Fréjus n'est pas exceptionnelle non plus. En effet, on retrouve dans le vide sanitaire augustéen de la rue de La Favorite à I yon et dans celui du Castro Pretorio à Rome, vers le milieu du I $^{\mathrm{er}} \mathrm{s}$. (Dressel, 1879), ou dans celui de Narbonne récemment découvert (plus de 200 amphores allongées sur un lit de galets au ${ }^{\text {er }}$ s.; Narbonne et la mer, 1990), bien des formes identiques à celles qui ont été choisies à Fréjus. Èn revanche, la disposition des amphores fréjusiennes, inclinées, pointe en haut ou pointe en bas, est originale. En effet, dans les exemples gaulois que nous avons évoqués, les amphores sont verticales ou horizontales; il en va de même des exemples italiens avec les trois à six niveaux, pointe en l'air, du Castro Pretorio, ou les lignes horizontales de la maison du Porche à Ostie (Van der Werff, 1986), ou les aménagements d'un bassin à poissons du port de Cosa (Mc Cann, 1987, p. 91 et fig. IV, 69), ou encore les nombreux exemples de l'Italie septentrionale et de la vallée du Pò (Carre, Cipriano, 1985 et particulièrement la note 1 ; - voir aussi la découverte récente d'un drainage composé de 2000 amphores la pointe en l'air dans la villa de Roncaglia di Ponte S. Nicolo à Padoue-Pesavento Mattioli, 1990). La disposition inclinée n'est pas davantage retenue pour la construction des murs de soutènement de Carthage, composés d'amphores horizontales alternant avec des lits de terre (Delattre, $1894 ; 1907$ ), ni pour l'incroyable dispositif de Turin qui aurait compté 1350000 amphores placées verticalement, la pointe en l'air et remplies d'argile ... (Dressel, 1879, p. 193).

Ce rapide tour d horizon souligne l'originalité de la disposition des amphores des vides sanitaires de la Porte d'Orée sans pour autant expliquer les raisons de ce choix. 


\section{LES AMPHORES 5}

\section{NOUVELLES PRODUCTIONS DE LA RÉGION DE FRÉJUS}

\section{UNE AMPHORE À FOND PLAT TIBÉRIENNE}

Dans le vide sanitaire de l'esplanade, une amphore à lèvre à double inflexion externe (Inv. SF. 09, fig. 7) et fond très certainement plat (il manque), appartient, comme le révèle sa composition, à la production fréjusienne (cf. infra, annexe I). C'est la confirmation d'un premier indice mis en évidence avec l'analyse d'un col analogue, il y a quelques années (Fontes el alii, 1981). Désormais rattachées à la période tibérienne par la date consulaire peinte sur le col du vide sanitaire, ces amphores marquent la plus ancienne fabrication connue à Fréjus. Le modèle à lèvre à double inflexion externe s'inscrit dans un large mouvement de productions ponctuelles et diverses qui se développe dans le Midi depuis la période augustéenne (Laubenheimer, 1989).

\section{Des DRessel 2/4 FlaVienNes}

Dans le vide sanitaire du bassin, un groupe de Dr. 2/4 à pâte blanche, riche en inclusions, s'est isolé facilement, au premier coup d'œil : il comprend toutes les Dr. 2/4 de la zone P7, plus un col en P13 (Inv. P13. F20) auxquels s'ajoute une amphore entière de la pièce 5 (Inv. F3. 1), soit un ensemble de 49 unités (fig. 11 et 12).

L'analyse par fluorescence $\mathrm{X}$ de six exemplaires confirme la cohérence du groupe par la composition de la pâte et atteste que ces Dr. 2/4 du dernier quart du $\mathrm{I}^{\mathrm{er}} \mathrm{s}$. ont été fabriquées à Fréjus ou dans la région. C'est une nouveauté (cf. infra, annexe I, p. 257).

La panse est longue et étroite, avec un diamètre maximal au niveau de l'épaulement à arête vive où se place l'attache inférieure des anses. Le col est presque cylindrique ; la lèvre forme un gros bourrelet fait par retournement de la pâte sur elle-même; les anses, faussement bifides, avec un sillon interne et un sillon externe, s'attachent sous la lèvre, les traces de soudure sont peu visibles. Le fond, plein, se termine en arrondi sur sa face externe; à l'intérieur, il comporte, ou non, un ombilic.

5 Au reste, le garum d'Antibes est transporté dans des pots, l'un deux a été retrouvé à Fos-sur-Mer (Liou, Corsi-Sciallano, 1989, p. 159).
L'échantillonnage disponible est suffisamment important pour qu'une étude de typologie statistique soit entreprise (Laubenheimer, 1985, p. $233 s q$.$) qui$ permette de définir les caractéristiques du ou des modules de la production fréjusienne. Quatorze paramètres, douze dimensions plus le poids et la contenance de l'objet, mettent en évidence deux modules (tabl. III). Le groupe principal rassemble dans un grand module toutes les amphores sauf une. On reconnaît une fabrication régulière dans la confection de la lèvre (EL, DL), du fond (I.F) et des anses (LA, EA) dont les dimensions suivent une distribution normale (fig. $21,1,2$ ) pour une trentaine d'échantillons (le test de normalité n'est pas réalisable pour les autres paramètres). La seule amphore qui se classe nettement à part (Inv. P7. 28) représente l'unique élément d'un module plus petit (fig. 11 et 12, P7. 28). Les caractéristiques technologiques sont. les mêmes, comme l'aspect général de l'amphore : il n'y a pas de différence sur la hauteur, les dimensions de la lèvre, de l'anse ou du fond. En revanche, la séparation, entièrement orientée sur la capacité, se fait par une série cohérente de paramètres discriminants : les diamètres de la panse et du col, plus étroits, la distance d'anse à anse plus faible, comme le poids et surtout la contenance, inférieure de près de 10 litres (fig. 21, 3, 4).

A la même époque, dans la zone P13, une Dr. 2/4 d'un modèle différent (fig. 17, P13. 17) présente une pâte orangée, avec des inclusions visibles qui, à l'analyse, est fréjusienne. L'amphore se distingue du groupe précédent par la forme de la panse, avec un diamètre maximal dans le tiers inférieur, et la courbe de l'anse qui s'accentue davantage vers le haut; on ne peut rien dire de la lèvre qui manque. Une estampille en creux marque le col : $M A R I$ (fig. 18). L'état fragmentaire de l'objet ne permet pas de conclure plus avant sur ses rapports avec le groupe défini. Au reste, la différence de couleur de la pâte, qui change avec le degré de cuisson, n'est pas un argument discriminant.

On restera prudent, pour le moment, sur l'origine, incertaine d'après les analyses, mais peut-être fréjusienne, de deux Dr. 2/4, l'une du bassin (P13. 02) et l'autre (SF. 16) de l'esplanade (fig. 3). D'après leurs caractères typologiques, elles n'entrent pas dans le groupe défini pour Fréjus (cf. infra, annexe I, p. 257). Il n'est pas exclu, cependant, que des variantes se dessinent peu à peu, élargissant la gamme des Dr. 2/4 fréjusiennes, comme l'amphore timbrée $M A R I$ le laisse présager. Au reste, on trouve, dans le catalogue, trois autres Dr. 2/4 non classées dont l'analyse physico-chimique n'est pas 
faite (fig. 3). Elles portent à cinq le nombre des Dr. 2/4 difficiles à classer par origine pour le moment.

La production de Dr. 2/4 gauloises n'est plus une exception, on compte maintenant plus de dix officines qui les ont fabriquées (Laubenheimer, 1989,

Tableau III - Mesures moyennes des amphores Dr. 2/4 fréjusiennes à pâte blanche. Dimensions en $\mathrm{mm}$; poids en $\mathrm{kg}$; contenance en I; rapport contenance/poids $(\mathrm{C} / \mathrm{P})$.

\begin{tabular}{|c|c|c|c|c|c|}
\hline & \multicolumn{3}{|c|}{ Grand module } & \multicolumn{2}{|c|}{ Petit module } \\
\hline & Échllon & Moyenne & Écart-type & Éch"lon & Valeur \\
\hline \multicolumn{6}{|l|}{ Lèvre } \\
\hline HL & 32 & 34 & 2 & 1 & 34 \\
\hline DL & 33 & 170 & 6 & 1 & 163 \\
\hline EL & 33 & 22 & 1 & 1 & 22 \\
\hline $\mathrm{Col}$ & & & & & \\
\hline LC: & 25 & 97 & 6 & 1 & 89 \\
\hline DIC & 21 & 62 & 5 & 1 & 64 \\
\hline \multicolumn{6}{|l|}{ Anse } \\
\hline LA & 29 & 54 & 3 & 1 & 49 \\
\hline EA & 29 & 28 & 2 & 1 & 27 \\
\hline HH & 11 & 59 & 5 & 1 & 58 \\
\hline AAA & 8 & 231 & 10 & 1 & 208 \\
\hline \multicolumn{6}{|l|}{ Panse } \\
\hline LP & 16 & 284 & 7 & 1 & 218 \\
\hline \multicolumn{5}{|l|}{ Fond } & 81 \\
\hline $\begin{array}{c}\text { Hauleur } \\
\text { lolale }\end{array}$ & 8 & 1146 & 29 & 1 & 1105 \\
\hline Poids & 10 & 18,8 & 1,4 & 1 & 14 \\
\hline Contenance & 8 & 28 & 3 & 1 & 17,5 \\
\hline Rapport C/P & & 1,5 & & & \\
\hline
\end{tabular}

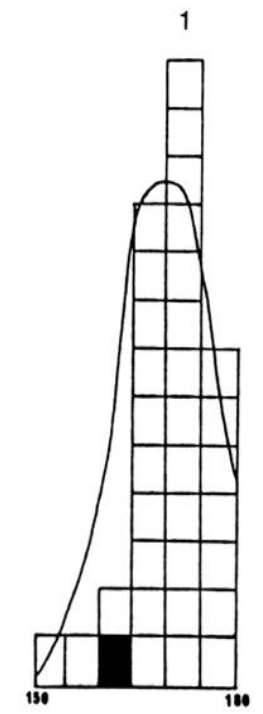

Diamètre lèvre

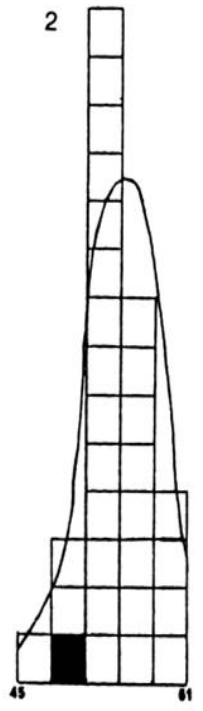

Largeur anse

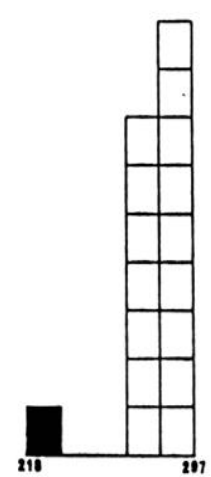

Diamètre panse fig. 4) avec des formes d'une grande variété. Le groupe fréjusien n'est pas très éloigné morphologiquement de certaines productions de Tarraconaise avec lesquelles on aurait pu le confondre pour le profil de la lèvre, du col, des anses, du pied... Par chance, le matériel entier de Fréjus et celui de douze

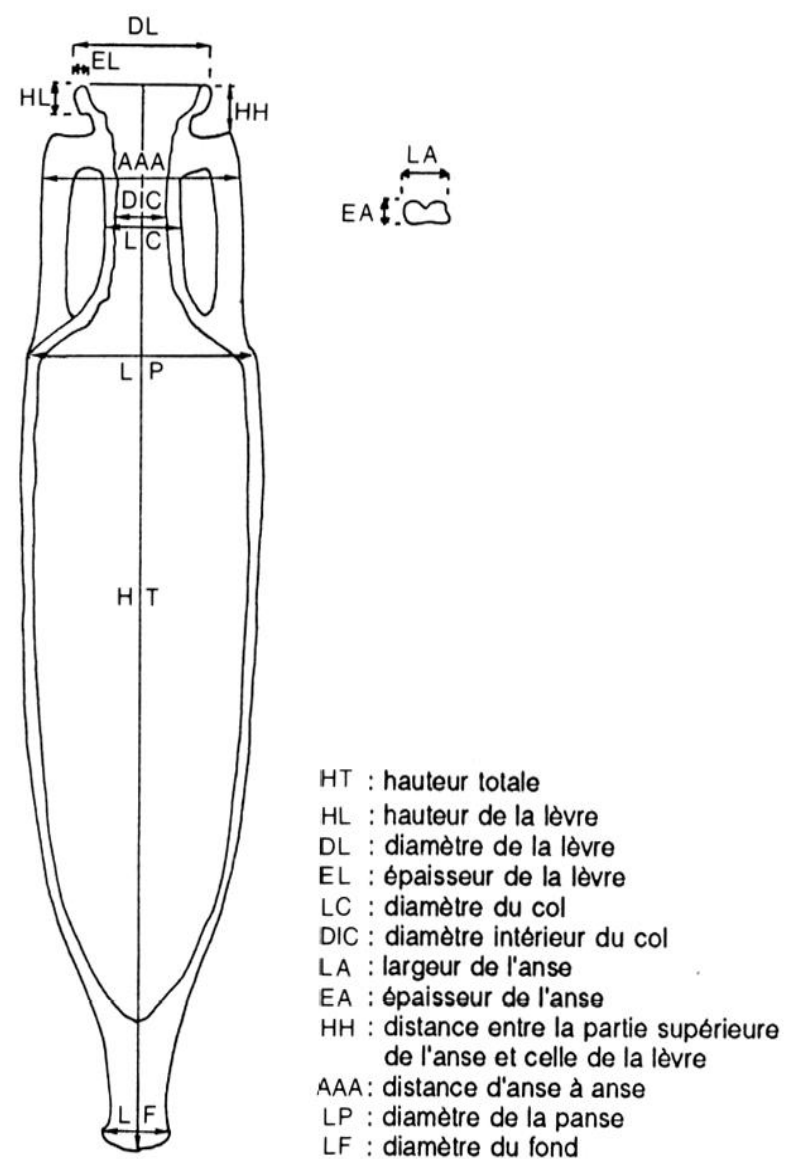

Fig. 21 - Distribution des amphores Dr. 2/4 fréjusiennes à pàte blanche. Suivant le diamètre de la lèvre et la largeur de l'anse, les amphores forment un seul groupe et la distribution suit une loi normale qui montre la régularité du geste (en noir, l'amphore de petit module). La largeur de la panse et la capacité séparent les amphores en deux groupes de grand et petit module (en noir).

Dimensions en millimètres et capacités en litres. 
Tableau IV - Mesures moyennes des amphores Dr. 2/4 des épaves de Tarraconaise (d'après Corsi-Sciallano, Liou, 1985 , p. 167).

\begin{tabular}{|c|c|c|c|c|c|}
\hline RÉFÉRENCE & HAUTEUR & DIAM. MAX. & POIDS & CAPACITÉ & RAPPORT C/P \\
\hline Planier $1 . .$. & $85 \mathrm{~cm}$ & $31,7 \mathrm{~cm}$ & $14 \mathrm{~kg}$ & 27,751 & 1,98 \\
\hline 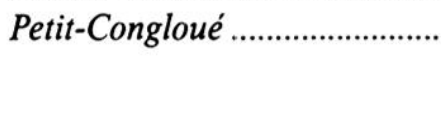 & 102,95 & 30,75 & 17,31 & $\begin{array}{c}26,56 \\
\text { (mais de } \\
23 \text { à 30) }\end{array}$ & 1,53 \\
\hline 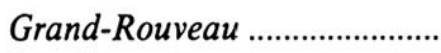 & 101,62 & 30,29 & 16,63 & 26,7 & 1,59 \\
\hline 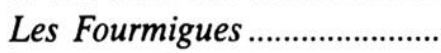 & 104,91 & 31,2 & 18 & 28,66 & 1,62 \\
\hline Dramont $B$ & 92,8 & 31,2 & 18,5 & 26,8 & 1,50 \\
\hline 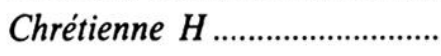 & 86,5 & 32 & 17 & $26 \mathrm{ca}$ & 1,52 \\
\hline 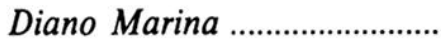 & 93,75 & 34,12 & - & 33 & - \\
\hline 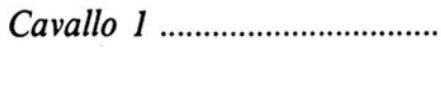 & 105,37 & 29,6 & & $\begin{array}{c}27,5 \\
\text { (1 mesure) }\end{array}$ & - \\
\hline 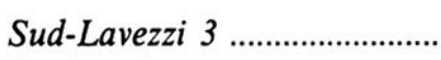 & 87,3 & 32,7 & 15 & 27,75 & 1,86 \\
\hline Perduto 1 & 88 & 32 & & & \\
\hline Bará & 104 & 29 & & & \\
\hline 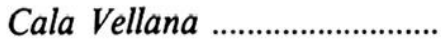 & 104,5 & 28,5 & & & \\
\hline
\end{tabular}

épaves de Tarraconaise permet d'établir des comparaisons précises fondées sur ces paramètres importants que sont la hauteur totale, le diamètre maximal, le poids et la contenance (tabl. III et IV, d'après Corsi-Sciallano, Liou, 1985, p. 167) et d'établir des différences. Ainsi, il apparaît que les Dr. 2/4 de Fréjus sont systématiquement plus hautes, avec une panse plus étroite, elles pèsent en gènèral un peu plus lourd et leur rapport contenance/poids est moins bon que celui des tarraconaises. Au reste, la panse étroite et longue des fréjusiennes pourrait bien être une caractéristique régionale. En effet, un atelier à Cannes tourne des Dr. 2/4 dont le profil est très proche de celui des fréjusiennes (Laubenheimer, 1989, fig. 6). On sait qu'on en fabriquait vraisemblablement aussi à Antibes ou dans sa région : en témoignent la mention Antipolitanum sur un petit fragment de col Dr. 2/4 trouvé à Ostie, peu éloquent à vrai dire en matière de typologie, parce que très petit (communication C. Panella); mais plus signifiante est l'amphore entière trouvée à Londres (Yule, 1989), attribuée également à Antibes par l'inscription peinte sur le col. Elle présente la même forme de panse que celle des fréjusiennes, avec un diamètre maximal sous l'attache inférieure des anses, mais sa capacité de $8,9 \mathrm{l}$ est nettement inférieure à celle du petit module de Fréjus $(17,5 \mathrm{l})$; la lèvre est plus verticale et les anses forment un coude plus accentué par une protubérance. Mais il y a aussi d'autres variantes, comme l'amphore flavienne d'Augst, aux anses très coudées, qui transporte du flos d'Antibes (Martin-Kilcher, 1990) ${ }^{6}$.

\section{UNE VARIANTE DE LA FORME DRESSEL 14 (?)}

Dans le vide sanitaire, en P13, l'amphore de forme bâtarde Dressel 14 (?) timbrée MARI présente une pàte identique à celle de la Dr. 2/4 frappée au même nom : nous avons affaire ici encore à une production locale (cf. infra, annexe I, p. 257) totalement inédite jusqu'alors dans la région et difficile à classer : Dr. 14, H. 70 ou P. 1 ? On ne connaît pas en Gaule, actuellement, de fabrication de Dr. 14 ou de H. 70. Le seul exemplaire fréjusien est, bien sûr, insuffisant pour définir un nouveau type. Les Pascual 1 de tradition tarraconaise y sont peu frabriquées : aux ateliers de Montans (Tarn) et de Corneilhan (Hérault) s'ajoute celui de Sainte-Cécileles-Vignes (Vaucluse) (Meffre, à paraître). Leurs productions, très différenciées les unes des autres, se séparent nettement de l'amphore de Fréjus.

En livrant cette moisson de résultats nouveaux, les vides sanitaires incitent à voir tout autrement la place de Fréjus et de sa région dans la production des amphores qui s'affirme désormais de Tibère aux Flaviens. Depuis quelques années déjà, grâce aux

6 Cf. note 5 . 
fouilles, aux prospections et aux analyses de pâte, on sait qu'on y a fabriqué, diverses séries d'amphores à fond plat, des G. 5, des G. 4 et des amphores à lèvre à double inflexion externe (Brentchaloff, 1980 ; Laubenheimer, 1985) et une autre forme encore : FréjusLenzbourg (Brentchaloff, 1988; Brentchaloff, Picon, 1990). S'y ajoutent maintenant les Dr. 2/4 et les Dr. 14 (?). Plusieurs ateliers de potiers sont repérés dans et autour de la ville à forte tradition céramique; cependant, dans leur majorité, les centres artisanaux restent mal connus, faute de fouille.

L'organisation de la production se montre difficile à cerner, mais l'idée d'une certaine sectorisation se fait jour: l'atelier du Pauvadou se consacre presque exclusivement à la fabrication des G. 5 , tandis que les G. 4 ou les Dr. 2/4 sont tournées ailleurs. On trouve un autre indice d'organisation avec l'estampille $M A R I$ : dans la même officine, on tourne des Dr. 2/4 et des Dr. 14 (?) et, selon toute vraisemblance, on moule aussi des tuiles, car les trois types d'objets portant le même sigle $M A R I$ sont locaux (fig. 18); les tuiles de Mari se répandent très largement à Fréjus et dans sa région (Brun et alii, 1984). Il s'agit sans doute d'un atelier à production diversifiée, comme on en connaît beaucoup, destiné aux matériaux de construction et aux amphores. C'est peut-être aussi le cas de celui de Clarianus, dans la vallée du Rhône, qui signe ainsi des briques et des tuiles, alors que le même timbre abrégé, CLAR, apparait sur des amphores G. 1. On utilise la même signature sur des objets moulés et sur des objets tournés qui relèvent de techniques différentes, ce qui pose, encore une fois, le problème de l'identité du signataire: un artisan maîtrisant plusieurs techniques, un contremaître, un propriétaire...?

Les amphores de Fréjus sont essentiellement liées au commerce du vin. C'est le rôle traditionnel des G. 4, G. 5 et des Dr. 2/4. S'ajoute maintenant l'amphore fréjusienne à lèvre à double inflexion externe. On sait, en effet, que la viticulture était florissante et d'un bon rapport : en témoigne ce récit de Columelle $(\mathrm{IV}, 3,6)$ à l'époque d'Auguste, où Paridius Veterensis, vigneron à Fréjus, peut se permettre d'offrir cn dot à sa fille aînée le tiers de ses vignes sans voir se réduire le fruit de sa vendange; plus encore, il dote par la suite sa seconde fille comme l'aînée et conserve toujours intacts ses revenus. C'est un viticulteur de talent, certes, qui montre de quelle maîtrise on était capable dans la région au début de notre ère! Fréjus est, au reste, une ville dynamique où le stationnement de la flotte, sans doute jusqu'au début de l'époque flavienne (Reddé, 1986, p. 171), a donné une forte impulsion à l'économie. A n'en pas douter, une bonne part des amphores fréjusiennes sont utilisées pour exporter le vin régional. Néanmoins, les G. 4 et les G. 5 , nous le savons maintenant, ont aussi transporté, pour une petite partie, jusqu'à l'époque de Néron, des vins d'importation arrivés en vrac dans des bateaux chargés de dolia à poste fixe (Hesnard et alii, 1988). C'était peut-être le cas à Fréjus, encore faudrait-il y trouver les horrea vinaria équipés de dolia nécessaires au déchargement des bateaux.

A la production des Dressel $2 / 4$ de la région fréjusienne, s'ajoute celle de Saint-Cassien à Cannes et celle d'Antibes, le long de la côte, qui nous invitent à poser en termes nouveaux la question de la production et de l'exportation des sauces de poisson parallèlement $a u$ vin. En effet, à trois reprises, des exemples montrent que des Dr. 2/4 d'Antibes sont utilisées pour commercialiser à longue distance des saumures ou des sauces de poisson : de la muria à Ostie, du liquamen de maquereaux à Londres (Laubenheimer, 1989, p. 107) et du flos à Augst (MartinKilcher, 1990). On sait aussi que Fréjus expédiait de la muria à Vindonissa dans des amphores à fond plat (Brentchaloff, Picon, 1990). Utilisait-on aussi ici, comme à Antibes, des Dr. 2/4 pour transporter des sauces de poisson? La présence de résine dans deux Dr. 2/4 du vide sanitaire de la Porte d'Orée (cf. infra, annexe II, p. 260, analyse en chromatographie en phase gazeuse) ne suffit pas pour trancher. En revanche, on soulignera que la côte était bien équipée pour la pêche (notamment, Donnadieu, Vadon, 1926-1928). Les vestiges de viviers et de bassins n'y sont pas rares. Pline précise qu'on fabriquait de l'allex à Fréjus $(\mathrm{NH}, 31,85)$. Il vante aussi la muria d'Antibes $(N H, 31,94)$ et l'on sait par Martial qu'elle était faite avec du thon $(4,88 ; 13,103)$ et expédiée en amphore à Rome $(13,103)$. Parallèlement au vin, la production et le commerce des poissons et de leurs dérivés tient à Fréjus et dans la région une place certainement importante. Le port suivrait-il un modèle développé depuis longtemps déjà sur la côte étrusque, à Cosa : on y exporte le vin des Sestii en même temps que les amphores à poisson (Mc Cann, 1987, p. $321 s q)$.

\section{DIVERSITÉ DES IMPORTATIONS (Tabl. V)}

Les amphores des vides sanitaires sont constituées pour plus de la moitié d'emballages locaux avec 57 exemplaires sur un total de 94 (fig. 22, 3). Les importations se distribuent inégalement entre plusieurs origines (fig. 22, 4). 
Tableau $\mathrm{V}$ - Distribution par origine des amphores des vides sanitaires (nombre minimum d'individus).

\begin{tabular}{|c|c|c|c|c|}
\hline & & $\begin{array}{l}\text { Esplanade } \\
(\text { vers }+30)\end{array}$ & $\begin{array}{c}\text { Bassin } \\
\text { (Flavien) }\end{array}$ & Total \\
\hline 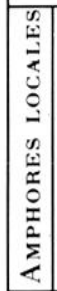 & $\begin{array}{l}\text { Gaule } \\
\text { Lèvre à double } \\
\text { inflexion externe } \\
\text { Dr. } 2 / 4 \text { Fréjus } \\
\text { Dr. } 14(?) \\
\text { G. } 5 \\
\text { Autres }\end{array}$ & 4 & $\begin{array}{r}49 \\
1 \\
1 \\
1 \\
\end{array}$ & 57 \\
\hline 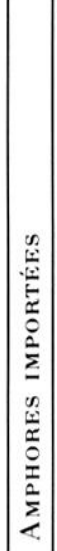 & $\begin{array}{l}\text { Italie } \\
\text { Dr. } 2 / 4 \text { campanienne } \\
\text { Péninsule ibérique } \\
\text { Dr. } 2 / 4 \text { tarraconaise } \\
\text { Dr. } 7 \\
\text { Dr. } 9 \\
\text { Dr. } 7 / 11 \\
\text { P. VII } \\
\text { Dr. } 20 \\
\text { H. } 70 \\
\text { Afrique } \\
\text { O. LIX } \\
\text { Non classées } \\
\text { Dr. } 2 / 4 \\
\text { Indéfini }\end{array}$ & $\begin{array}{l}3 \\
1\end{array}$ & $\begin{array}{l}2 \\
3 \\
3 \\
1 \\
8 \\
4 \\
1 \\
1 \\
1 \\
3 \\
1\end{array}$ & $\begin{array}{r}1 \\
26\end{array}$ \\
\hline & Total & 18 & 76 & 94 \\
\hline
\end{tabular}

La plus forte part revient à la Péninsule ibérique (26 sur 37 exemplaires) et plus précisément à la Bétique (23 exemplaires sur 26) qui tient la première place avec ses salsamenta et sauces de poisson essentiellement, soit 17 exemplaires sur 23.

Quatre Dr. 7/11 fragmentaires et quatre Dr. 9 (des vides sanitaires de l'esplanade et du bassin) identiques à celles du drain augustéen de La Longarina à Ostie (Hesnard, 1980); huit Pompéi VII (Zevi, 1966, p. 234, note 77), les plus nombreuses ici, caractérisées par un col très large prévu pour emmagasiner des morceaux de poisson salé, comportent des variantes nombreuses et encore mal classées qui expliquent en partie la difficulté à leur donner une dénomination unique. Voici, par exemple, quelquesunes de leurs appellations : Dr. 38-39, Pélichet 46 (Pélichet, 1946), ou Beltrán IIA (Beltrán Lloris, 1970), ou Ostia LXIII (Panella, 1973)... Cinq amphores entières à Fréjus ont un poids moyen régulier de $20 \mathrm{~kg}$ (écart-type : 1) pour une contenance de 33 I (écart-type: 2), avec un rapport contenance/ poids de 1,7. Produites depuis la fin de l'époque augustéenne, elles sont fréquentes au cours du $\mathrm{I}^{\mathrm{er}} \mathrm{s}$., par exemple, sous Claude, dans l'épave de Port-
Vendres II (Colls et alii, 1977), à Pompéi avant 79 et à Ostie sous les Flaviens et jusqu'au début du ${ }{ }^{\mathrm{e}} \mathrm{s}$. (Panella, 1973, p. 512).

Les Dr. 20 transportant l'huile sont rares (5 exemplaires sur 23), contrairement aux drainages de la région de Lyon. Leur présence à Fréjus est, au reste, bien attestée, comme dans les nécropoles de Saint-Lambert et du Pauvadou.

Du vin de Bétique, il n'y a qu'un seul témoignage avec une amphore $H .70$ dont on sait qu'elle contenait des vins cuits, le defrulum ou la sapa, souvent utilisés comme ingrédients et comme conservateurs (Laubenheimer, 1990); cette amphore apparaît un peu partout en Gaule, le long des grands axes de circulation, mais, le plus souvent, en quantité très modeste.

Trois amphores Dr. 2/4 attribuables vraisemblablement à la Tarraconaise s'inscrivent dans un trafic bien établi, jalonné par sept épaves le long de la côte provençale (Corsi-Sciallano, Liou, 1985, fig. 1).

Une seule amphore Dr. 2/4 sur 38 exemplaires vient de la région de Pompéi : il y a, en effet, peu d'amphores campaniennes en Gaule à cette époque.

Lne seule amphore (Ostia LIX) correspond sans doute aux premières importations africaines $d u \mathrm{I}^{\mathrm{er}} \mathrm{s}$. et dix autres, fragmentaires, ne sont pas attribuables.

On retrouve ici la gamme des principaux produits habituellement importés au $\mathrm{I}^{\mathrm{er}}$ s. de notre ère, à quelques exceptions près (fig. 22, 5). Les vins grecs, par exemple, font défaut, mais on sait qu'il y a une amphore rhodienne dans une couche de l'habitat (cf. infra, annexe I, p. 257).

Les trois denrées importées (vin, huile et poisson) sont produites dans la région de Fréjus, ellemême exportatrice. C'est là une réalité habituelle dans le monde romain, où la vitalité des échanges et le niveau de vie se traduisent par la consommation simultanée de produits locaux et importés.

La prédominance des importations de salaisons et sauces de poisson $(45 \%)$ sur les vins $(13 \%)$ surprend. Elle est à l'inverse de ce que l'on trouve habituellement, à Lyon, par exemple, à l'époque augustéenne (Becker et alii, 1986, fig. 20), ou à l'époque flavienne (Dangréaux, Desbat, 1987-1988, fig. 22 : $18 \%$ de vins importés pour $16 \%$ d'huile et $16 \%$ de saumure). L'échantillonnage des vides sanitaires n'est pas, en effet, le reflet de la consommation des denrées à Fréjus, mais celui d'un tri qu'on ne saurait comparer aux résidus d'un habitat. Les amphores recyclées comme matériaux de construction ont èté choisies en fonction de leur forme et de leur solidité. les formes longues sont les mieux adaptées ici. En 


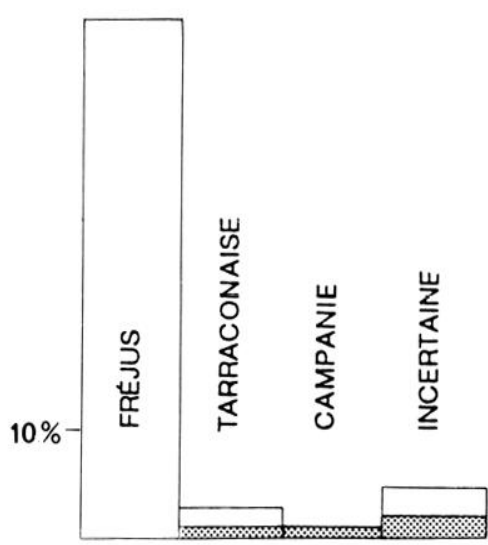

1- Distribution des Dr. 2/4

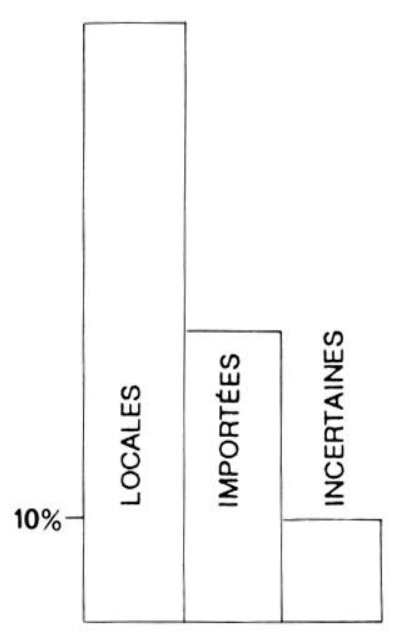

3. Comparaison entre amphores locales et importations

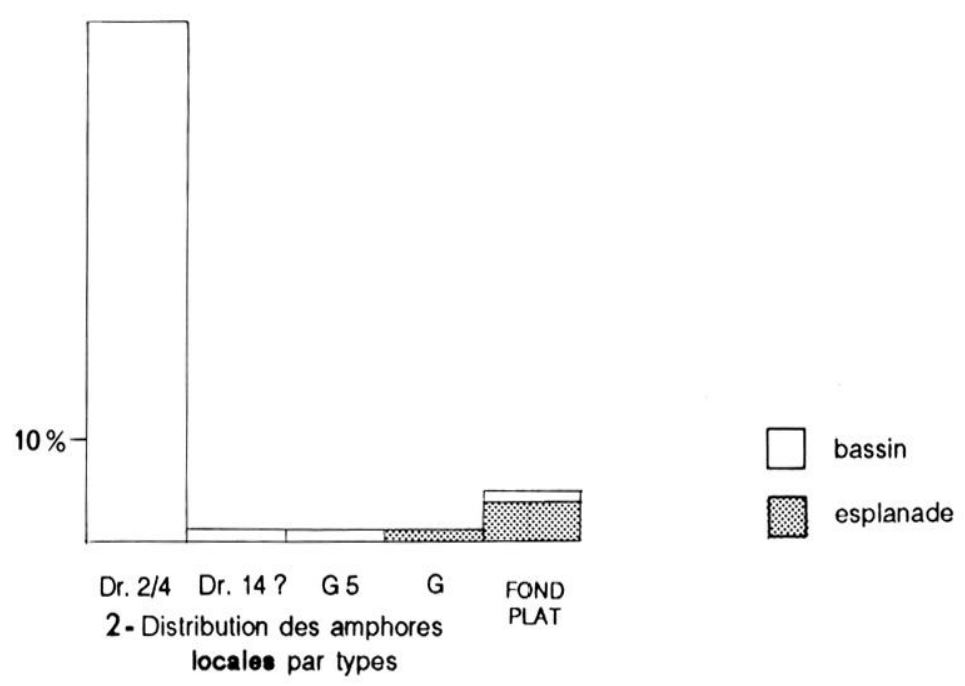

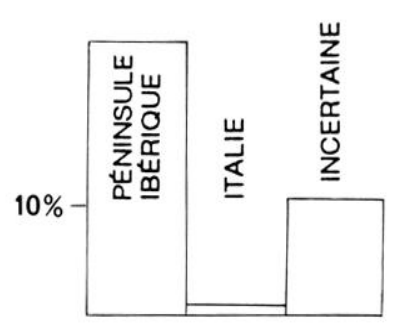

4- Distribution des amphores importées par origine

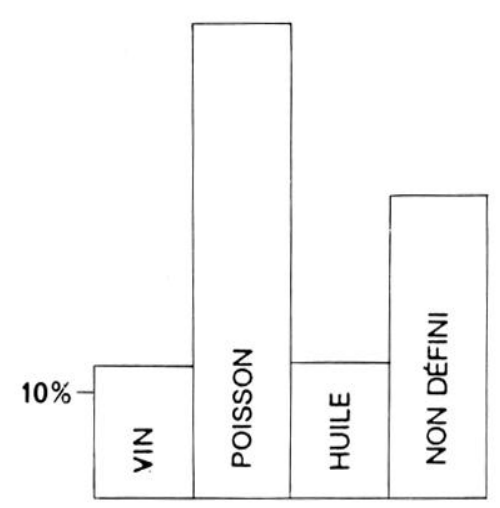

5- Produits importes dans les amphores

Fig. 22 - Distribution des amphores par type, par origine et par contenu.

revanche, les emballages qui ne conviennent pas ont été systématiquement éliminés.

Pour isoler de l'humidite les vastes surfaces de l'esplanade et du bassin, on a utilisé des centaines, voire des milliers d'amphores, en plusieurs couches inclinées, suivant une disposition originale. Des sondages ponctuels ont livré à l'étude un échantillon de 95 individus dont nous jugeons mal s'il est représentatif de l'ensemble. La distribution des objets, en effet, ne semble pas régulière : plus de la moitié du lot total se trouve correspondre à une seule série d'amphores locales regroupées en un même endroit, tandis qu'ailleurs, se manifeste une plus grande diversité (fig. 22).

Nous avons sans doute affaire à un échantillonnage qui, bien que remarquable par son état de conservation et sa qualité, n'est représentatif que des secteurs fouillés et des formes choisies. Il a de bonnes raisons de ne donner ni une image réelle des amphores produites à Fréjus, ni de celles qui y ont circulé. En revanche, il offre un effet de surprise, découvrant que les amphores fréjusiennes les mieux connues, les G. 5 , sont quasiment absentes, mais le répertoire des productions locales s'enrichit de plusieurs modèles avec, notamment, une remarquable série de Dr. 2/4 (fig. 22,2), désormais bien caractérisée. Plus encore, une production régionale semble se dessiner autour de Fréjus, Cannes et Antibes. Ces emballages, traditionnellement utilisés pour le vin, ont pu servir, à Fréjus comme à Antibes, à transporter des sauces de poisson. Mais il n'est pas exclu qu'ils aient commercialisé indifféremment vin et 
poisson. Il est désormais manifeste, comme le révèlent les lituli picti récemment découverts, que les Dr. 2/4 ont eu un double usage : transport de vin et transport de poisson. Pourquoi ? Le choix (par qui?) de la forme de l'emballage en fonction du produit transporté est une réalité parfois complexe qui appelle à poursuivre la recherche.

Origine des documents.

Ph. Folliot, Centre Camille Jullian, C.NRS, Université de Provence, service photographique : fig. $3 ; 4$; fig. 5 , SF. $16 ; 6 ; 7$; fig. 11, P7. 03, P7. 04, P7. 15, P7. 17, P7. 41, P7. 28 ; fig. 13, P7. 40, P7. 43, P7. 58, P7. 60, P7. $62 ; 16 ; 17 ;$ fig. 18,1 et 2 ; $19 ; 20$.
La riche collection des amphores rassemblées au $\mathrm{I}^{\mathrm{er}} \mathrm{s}$. dans les vides sanitaires de la Porte d'Orée fait éclater la vitalité de l'économie de la région fréjusienne, fortement organisée pour la production et bien placée pour les échanges.

Fanette Laubenheimer

Service archéologique municipal de Fréjus : fig. 2 et 9 . F. Laubenheimer : fig. 5, P7. 55; fig. 11, P7. 21, P7. 28; fig. 13, P13. F16; fig. 18, 3 .

Isabelle Béraud, Service archéologique municipal de Fréjus : fig. $1 ; 2 ; 8 ; 10$; fig. 16, P13. 01; fig. 19, P13. 16, P13. 12 . Kathy Vaiden-Gicquel : fig. $3 ; 4 ; 5 ; 6 ; 7 ; 12 ; 14 ; 15 ; 17$; fig. 19, P13. 18; fig. 20, P 13.06 . 


\section{ANNEXE I}

\section{Analyses d'amphores de Fréjus}

\section{par Maurice PICON*}

Les 22 exemplaires sélectionnés, dont trois exemplaires de référence $\left(\mathrm{n}^{\text {os }} 1\right.$ à 3 , cf. tabl. VI) ont été analysés par fluorescence $\mathrm{X}$. Vingt constituants chimiques ont été dosés sur chaque exemplaire, soit dix constituants majeurs : $\mathrm{Na}_{2} \mathrm{O}, \mathrm{K}_{2} \mathrm{O}$, $\mathrm{MgO}, \mathrm{CaO}, \mathrm{MnO}, \mathrm{Al}_{2} \mathrm{O}_{3}, \mathrm{Fe}_{2} \mathrm{O}_{3}, \mathrm{SiO}_{2}, \mathrm{TiO}_{2}, \mathrm{P}_{2} \mathrm{O}_{5}$, et dix traces : $\mathrm{Rb}, \mathrm{Sr}, \mathrm{Ba}, \mathrm{Ni}, \mathrm{Zn}, \mathrm{Cr}, \mathrm{Zr}$, La, Ce, V.

Seuls dix-sept constituants ont été conservés pour la classification, $\mathrm{Na}_{2} \mathrm{O}, \mathrm{P}_{2} \mathrm{O}_{5}$ et La ayant été éliminés pour des raisons de pollution et/ou d'imprécision de mesures.

I a classification a été faite par analyse de grappes en affinité moyenne non pondérée sur variables centrées réduites relatives aux dix-sept constituants conservés (fig. 23).

On ne pouvait pas espérer obtenir une classification satisfaisante à partir d'un aussi petit échantillonnage et compte tenu des importantes fluctuations de composition des céramiques issues des ateliers de la région de Fréjus, céramiques dont le laboratoire avait abordé l'étude à propos de la vaisselle commune en usage dans la région (Pasqualini, 1988). Il aurait été souhaitable par ailleurs que l'étude projetée des ateliers d'amphores de la région de Fréjus ait pu être faite avant ce travail. Cela aurait permis sans doute de préciser certaines attributions, encore n'est-ce pas certain, à cause des altérations de composition que présentent bon nombre des exemplaire étudiés. Ces altérations sont dues pour une part, à la surcuisson de certains exemplaires et pour une autre part, à un milieu d'enfouissement saumâtre; elles seront évoquées plus loin.

En procédant par élimination, on peut noter que le $n^{\circ} 22$ est italique et plus prćcisćment pompéien. Sa pâte rouge à minéraux noirs (pyroxènes) abondants est d'un type assez fréquent en Italie; on en connaît six groupes, ayant des compositions différentes, dans le cas des amphores Dr. 1 (Hesnard $e t$ alii, 1989). L'exemplaire Dr. 2/4 étudié ici, no 22 , se

\footnotetext{
* Laboratoire de céramologie (ERA 3) du CRA, 7, rue Raulin, 69365 Lyon Cedex 07.
}

rattache sans hésitation possible aux compositions du groupe pompéien, l'un des six groupes précédents. A l'intérieur de ce groupe, fort d'une cinquantaine d'exemplaires, le $n^{\circ} 22$ occupe une position un peu marginale due principalement à son pourcentage de magnésie, $\mathrm{MgO}$, légèrement plus élevé que ceux de la plupart des références pompéiennes. Cependant, il

Tableau VI - Liste des échantillons.

\begin{tabular}{|c|c|c|c|c|}
\hline & $\begin{array}{l}\mathrm{N}^{\circ} \\
\text { échantillon }\end{array}$ & $\begin{array}{l}\text { Type } \\
\text { amphore }\end{array}$ & Timbre & $\begin{array}{l}\mathrm{N}^{\circ} \\
\text { inventaire }\end{array}$ \\
\hline \multirow{4}{*}{$\begin{array}{l}\text { Pauvadou, } \\
\text { atelier de } \\
\text { potiers }\end{array}$} & 1 & G. 5 & & PAU 12 \\
\hline & 2 & G. 5 & & F1 \\
\hline & 3 & G. 5 & & F2 \\
\hline & 6 & tegula & MARI & PAU \\
\hline \multirow[t]{18}{*}{ Porte d'Orée } & 4 & P. 1 ou H. 70 & MARI & P13. 08 \\
\hline & 5 & Dr. $2 / 4$ & MARI & P13. 17 \\
\hline & 7 & Dr. $2 / 4$ & & P7. 04 \\
\hline & 8 & Dr. $2 / 4$ & & P7. 10 \\
\hline & 9 & Dr. $2 / 4$ & & P7. 17 \\
\hline & 10 & Dr. $2 / 4$ & & P7. 18 \\
\hline & 11 & Dr. $2 / 4$ & & P7. 28 \\
\hline & 12 & Fond plat & $\begin{array}{l}\text { marque } \\
\text { peinte }\end{array}$ & S.F. 09 \\
\hline & 13 & Rhodienne & & P5. M38C4 \\
\hline & 14 & Dr. $2 / 4$ & & P13. 01 \\
\hline & 15 & Dr. $2 / 4$ & & P13. 02 \\
\hline & 16 & Dr. $2 / 4$ & & P13. 07 \\
\hline & 17 & Dr. $2 / 4$ & & P13. 15 \\
\hline & 18 & Dr. $2 / 4$ & & P13. F20 \\
\hline & 19 & Dr. $2 / 4$ & & P13. 05 \\
\hline & 20 & Dr. $2 / 4$ & & S.F. 03 \\
\hline & 21 & Dr. $2 / 4$ & & S.F. 16 \\
\hline & 22 & Dr. $2 / 4$ & & S.F. 06 \\
\hline
\end{tabular}


n'est pas exclu que cette caractéristique soit due au milieu d'enfouissement saumâtre (Lemoine et alii, 1981). Quoi qu'il en soit, l'attribution à la région de Pompéi de l'exemplaire $n^{\circ} 22$ ne semble pas pouvoir ètre remise en cause.

L'exemplaire $\mathrm{n}^{\circ} 13$ qui n'appartient pas aux vides sanitaires, mais à la pièce 5 , est rhodien; ses caractéristiques de composition sont parmi les plus répandues à Rhodes, avec de hauts pourcentages de magnésie $(\mathrm{MgO})$, de chrome $(\mathrm{Cr})$ et de nickel $(\mathrm{Ni})$. Comparé aux quelques 150 exemplaires constituant les références des ateliers rhodiens, l'exemplaire $n^{0} 13$ s'y intègre sans problème. Il s'agit donc bien semble-t-il d'un exemplaire provenant de l'île de Rhodes, et non de la Pérée rhodienne où ce type d'amphore a été produit également (Desbat, Picon, 1986). On peut noter enfin que tous les exemplaires ètudiés jusqu'ici, trouvés en Gaule, soit une vingtaine environ, proviennent de la Méditerranée orientale, et que l'on a rencontré aucune imitation rhodienne qui aurait été fabriquée en Occident.

On a, par ailleurs, distingué, dans le diagramme (fig. 23), quatre groupes désignés par les lettres A, B, $\mathrm{C}$ et $\mathrm{D}$, auxquels se rattachent différents exemplaires en position marginale.

Le groupe $\mathrm{D}$, de loin le plus hétérogène des quatre, comprend une référence, $\mathrm{n}^{0} 2$, et trois exemplaires $\mathrm{n}^{\text {os }} 14,17$ et 20 qui se distinguent de l'exemplaire $n^{\circ} 2$ par une pâte comportant, sur un fond rouge, de nombreuses inclusions blanches. On peut laisser de côté le cas de la référence $\mathrm{n}^{\circ} 2$, manifestement mal classée dans le groupe D. Seule référence non calcaire des ateliers de Fréjus, elle est réunie aux exemplaires $n^{\text {os }} 14,17$ et 20 , également non calcaires, pour former le groupe $\mathrm{D}$ (seul groupe non calcaire de l'échantillonnage étudié).

Les trois exemplaires $n^{\text {os }} 14,17$ et 20 ont en commun une pâte rouge à gros dégraissants de quartz, de feldspath et de mica noir. La faible altération de ce dernier minéral permet de supposer que les gisements d'argile utilisés se trouvent à proximité de terrains gneissiques ou granitiques, voire de micaschistes, ce qui peut correspondre à des productions de la région des Maures et de l'Estérel, ou à des productions de Tarraconaise, pour ne prendre en compte que les origines les plus vraisemblables. La distinction entre ces deux groupes d'origine, sur des critères de composition, est actuellement très problématique par suite de l'insuffisance des références dans l'une et l'autre région. Pour la Tarraconaise, ce sont surtout les amphores à pâte jaune, calcaire, largement minoritaires sur place, qui ont été étudiées par suite des problèmes de séparation qu'elles posent avec certaines productions rhodaniennes. Quant aux produc-

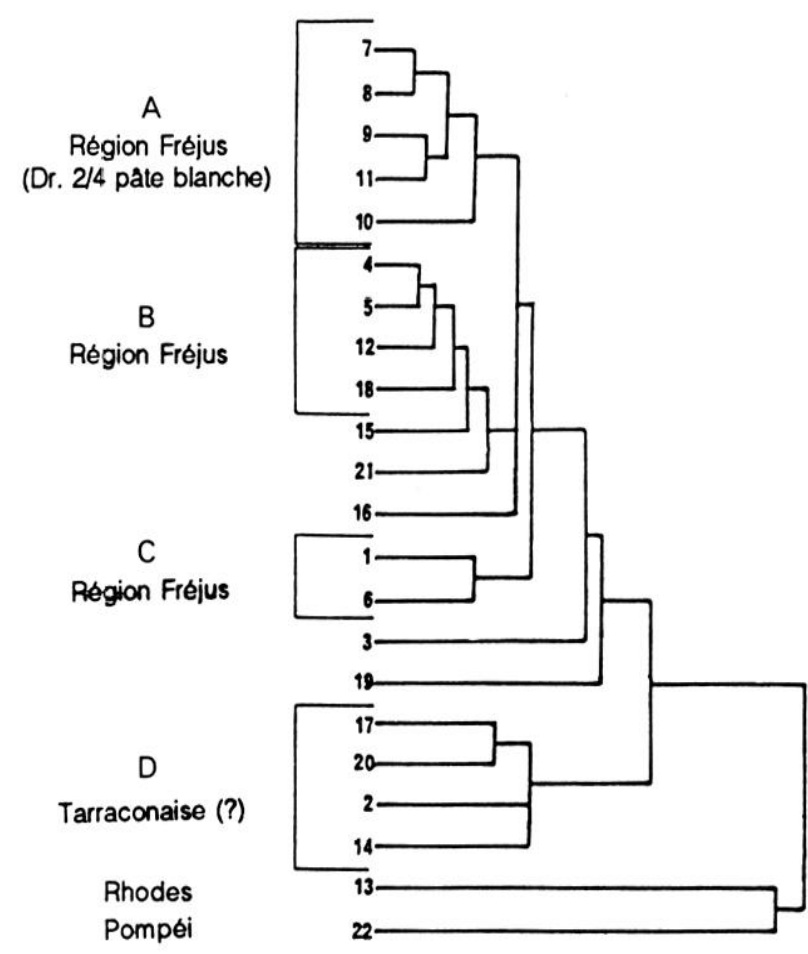

Fig. 23 - Classification ascendante hiérarchique des échantillons de Fréjus.

tions des Maures et de l'Estérel, ce sont encore celles à pâte calcaire qui ont été les plus étudiées, les autres n'étant guère connues que par l'atelier de Cavalaire. Cette insuffisance de la documentation géochimique, relative aux deux régions prises en compte, interdit de considérer comme significatif le fait que les exemplaires nos 14,17 et 20 ont des compositions qui sont, en l'état actuel des références disponibles, un peu plus proches de celles de Tarraconaise que de celles de Cavalaire. Si les données typologiques étaient en faveur d'une origine de Tarraconaise, on pourrait simplement ajouter que les compositions chimiques des pàtes ne s'opposent pas à une telle attribution, mais qu'il faudrait pouvoir disposer de références en beaucoup plus grand nombre pour qu'on ait quelque chance d'observer des ressemblances plus marquées et significatives.

Les groupes B et C correspondent aux deux principaux groupes de composition de la région de Fréjus, comme on peut le vérifier en introduisant dans la classification les quelques références d'atelier supplémentaires que l'on possède pour Fréjus et pour sa région, et les céramiques communes provenant des fouilles de Fréjus. On notera la présence, parmi les exemplaires qui se trouvent ainsi attribués à la région de Fréjus, des $n^{\text {os }} 4,5$ et 6 , amphores et tegula portant la marque $M A R I$. Si l'attribution à la 
région de Fréjus des exemplaires $n^{\text {os }} 12$ et 18 ne paraît pas soulever de problème, il convient d'être plus réservé pour les exemplaires $n^{\circ} 15,21$ et 16 dont le caractère marginal va en augmentant dans cet ordre. Il semble qu'on puisse exclure sans hésitation l'exemplaire le plus marginal, le no 16 , qui présente de plus des caractéristiques minéralogiques assez différentes des exemplaires de Fréjus. L'exclusion est moins évidente pour les exemplaires $n^{o s} 15$ et 21 , mais l'insuffisance des références ne permet pas de se prononcer.

Le cas de l'exemplaire $n^{\circ} 3$, servant de référence pour l'atelier du Pauvadou, est intéressant dans la mesure où il se signale par un taux anormalement élevé de baryum, caractéristique qu'il partage avec les autres références de ce même atelier ( $\mathrm{n}^{\text {os }} 1$ et 2 ). On a de fortes raisons de penser que ces pourcentages élevés de baryum sont dus à des phénomènes de pollution qui résultent de la présence d'un champ filonien à barytine à proximité de l'atelier du Pauvadou (Picon, 1987). Les céramiques fabriquées dans l'atelier du Pauvadou, mais enfouies sur différents sites de consommation extérieurs à l'atelier, n'ont pas $a$ priori de raison de présenter une semblable altération. C'est sans doute ce qui explique pour une assez large part le caractère marginal des références $n^{o s} 1$ à 3.

Le cas de l'exemplaire $n^{\circ} 19$ dont le caractère marginal est dù à un pourcentage anormalement élevé en rubidium reste isolé, ce qui ne permet pas de se prononcer sur son attribution éventuelle à la région de Fréjus. On ne pourrait le faire, comme pour les exemplaires nos 15 et 21 évoqués précédemment, que dans la mesure où les caractéristiques typologiques viendraient renforcer les fortes, mais insuffisantes, présomptions en faveur d'une origine locale ou régionale (comme le suggèrent les ressemblances de composition de ces exemplaires et des exemplaires originaircs de la région de Fréjus).

Il reste enfin à examiner le cas des cinq exemplaires de Dr. 2/4, nos 7 à 11 , qui constituent le groupe A. On serait tenté d'attribuer ces exemplaires à la région de Fréjus, si l'on considère qu'il s'agit d'exemplaires surcuits et que les différences de composition qu'ils présentent, par rapport au groupe B, correspondent pour l'essentiel aux altérations qui affectent très souvent les céramiques surcuites, et surtout les céramiques calcaires surcuites. Il s'agit essentiellement d'une perte de potassium (pourcentage moyen : 2,30 en A, contre 3,55 en B), et d'une fixation de sodium (pourcentage moyen : 1,54 en $A$, contre 0,98 en $B$ ), cette dernière étant plus importante que d'habitude, ce qui pourrait être mis en relation avec le caractère saumâtre du milieu d'enfouissement, lequel serait également responsable des pourcentages plus élevés de magnésium de ces exemplaires (pourcentage moyen : 1,94 en A, contre 1,64 en B). Il semble en tout cas acquis que ces exemplaires sont pour le moins originaires de la région de Fréjus, même si leur état d'altération, et celui des références, ne permettent pas d'être plus précis dans la localisation.

M. P. 


\section{ANNEXE II \\ Recherche de résine dans les amphores par Françoise FORMENTI*}

Deux amphores de type Dr. 2/4 à pâte blanche, qui appartiennent au lot découvert dans le vide sanitaire du bassin, dans la zone P7 : P7. 12 et P7. 31 ont été analysées par chromatographie en phase gazeuse après extraction des composés organiques au chloroforme et méthylation au diazométhane. Elles présentent toutes les deux des traces de résine; en particulier, on note la présence d'acide déhydroabiétique (fig. 24).

* Institut de chimie et physique industrielle (ICPI, Lyon), 31, place Bellecour, 69288 Lyon Cedex 02.
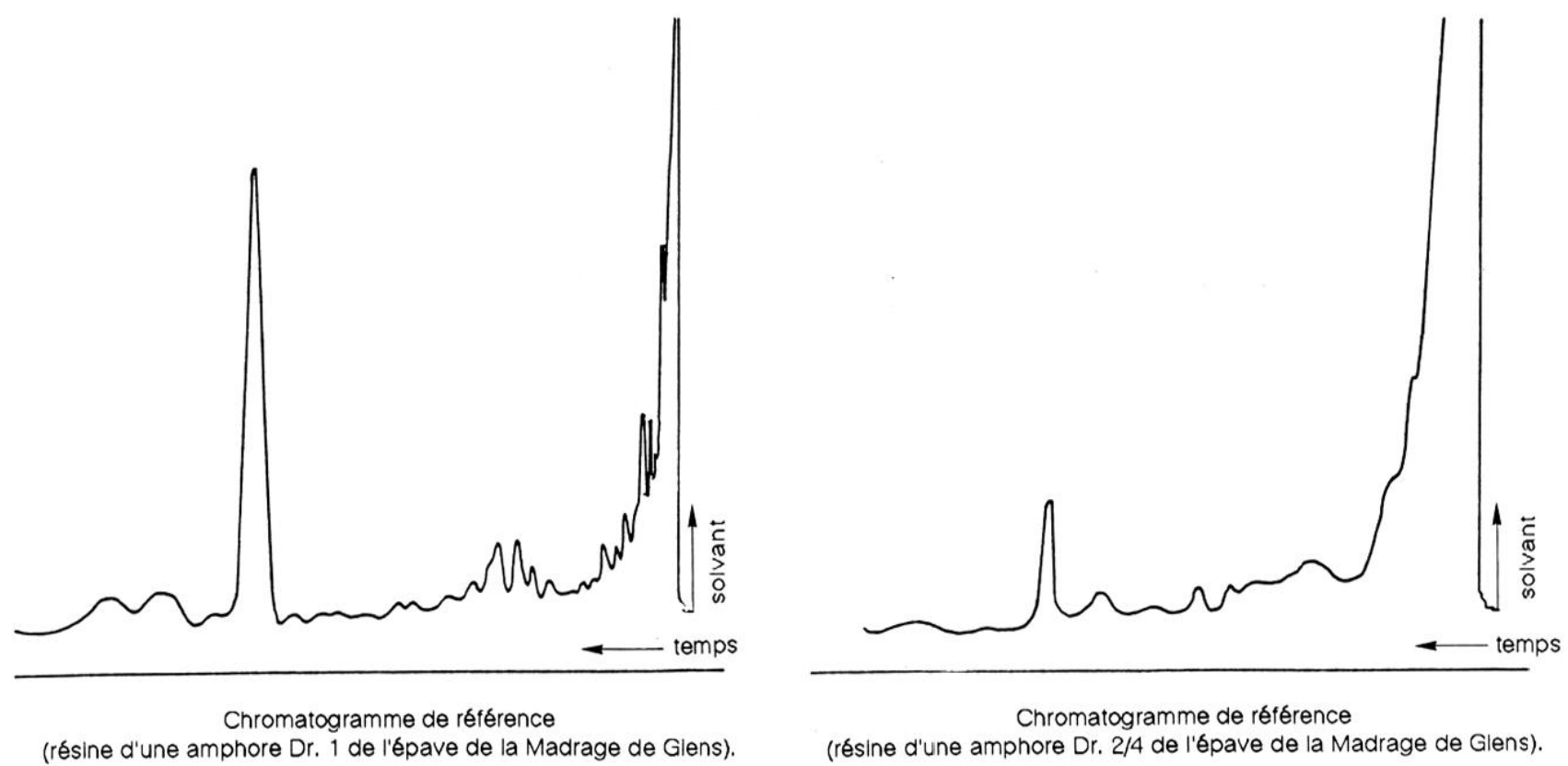

Fig. 24 - Méthylation au diazométhane. 


\section{ANNEXE III \\ L'inscription peinte sur amphore à fond plat du sondage $F$ par Bernard LIOU*}

Une des sept amphores "gauloises" issues du vide sanitaire révélé par le sondage $F$ porte une inscription peinte à l'encre noire (fig. 25) qui se lit ainsi :

\section{SILANO C VELLAEO TVTORE COS AMINN T LOC}

La première ligne doit se développer : L(ucio) (Iunio) Silano, C(aio) Vellaeo Tutore co(n)s(ulibus); elle indique, par le nom des consuls, une date qui se situe dans le second semestre de l'année 28 après J.-C. La lecture ne souffrc aucun doute, mais n'est pas pour autant facile. On commence, bien entendu, par la fin, où les lettres COS sont très claires. Le nom du second des deux consuls - son cognomen - se termine en -tore; j'ai cru d'abord lire -astore, Pastore, ce qui conduit à une impasse; la solution est en fait donnée par le nomen, qui n'a pas l'habituelle désinence en -io, mais celle, beaucoup plus rare, en -aeo; on lit même, assez aisément, -laeo; il suffit dès lors de consulter d'une part le tableau donné par W. Schulze, Zur Geschichte lateinischer Eigennamen, Berlin, 1904, p. 388-391, col. 2, des gentilices à désinence-aeus et, d'autre part, les fastes consulaires : le consul que nous cherchons est $C$. Vellaeus Tutor. Son collègue est $L$. Iunius Silanus, qui n'est désigné que par l'initiale de son prénom et son cognomen : à partir du moment où l'on est assuré de l'énoncé, on distingue des traces de toutes les lettres de la date consulaire ...

* Centre Camille Jullian, URA 284, Université d'Aix-Marseille 1, 29, avenue Robert-Schuman, 13621 Aix-en-Provence.
L. Silanus et $C$. Vellaeus Tutor ont été consuls suffects en 28 après J.-C. ? . Les consuls ordinaires de cette année là, $C$. Appius Iunius Silanus et $P$. Silius Nerua, étaient encore en charge le 7 avril; Silanus el Tutor sont attestés en date du 23 septembre par une dédicace découverte en 1958 à Cales ${ }^{8}$ et pour les 4 et 5 décembre par des labulae patronatus de Brescia ${ }^{9}$.

Cette amphore de la Porte d'Orée appartient au type que Fanette Laubenheimer avait baptisé «G(auloise) 7» et dans lequel elle a classé des produc-

7 A. Degrassi, I Fasti consolari dell'Impero romano, Rome, 1961, p. 9.

8 W. Johannovsky, Nuova epigrafe di Cales, in: Rendiconti dell'Accademia di archeologia di Napoli, XXXVII, 1962, p. 163-166 avec pl. XIV.

9 CIL, V, 4921 et $4922=$ Dessau 6099 a et 6099 ; A. Degrassi, Inscr. Italiae, 13, 1, p. 300.

Le sénatus-consulte Velleianum dont traite le Digesle, XVI, 1, est attribué par Ulpien à un couple de consuls, Marcus Silanus et Velleus Tutor, qu'il situe au plus tòt sous le règne de Claude, et même après : Et primo quidem temporibus diui Augusti, mox deinde Claudii edictis eorum (...). Postea factum est senatus consultum ... (Digeste, XVI, 1, 2). On ne connaît pas en fait ce couple de consuls : on a pensé (Mommsen) à $M$. lunius Silanus, consul durant toute l'année 46 , dont tous les collègues semblent au demeurant connus, ou à un homonyme qui aurait géré le consulat peu avant 56 , avec un collègue dont le prénom semble être A(ulus) : cf. $P I R^{2}$, IV, fasc. 3 (1966), no 864 . Pas de traces d'un consul Vellaeus Tulor autre que Caius, le collègue de L. Iunius Silanus dans le second semestre de 28. La Lex Iunia Vellaea mentionnée par Gaius, Inst., 2, 134 et par le Digeste, XXVIII, 2, 29, etc., porte leur nom, comme sans doute le sénatus-consulte. 


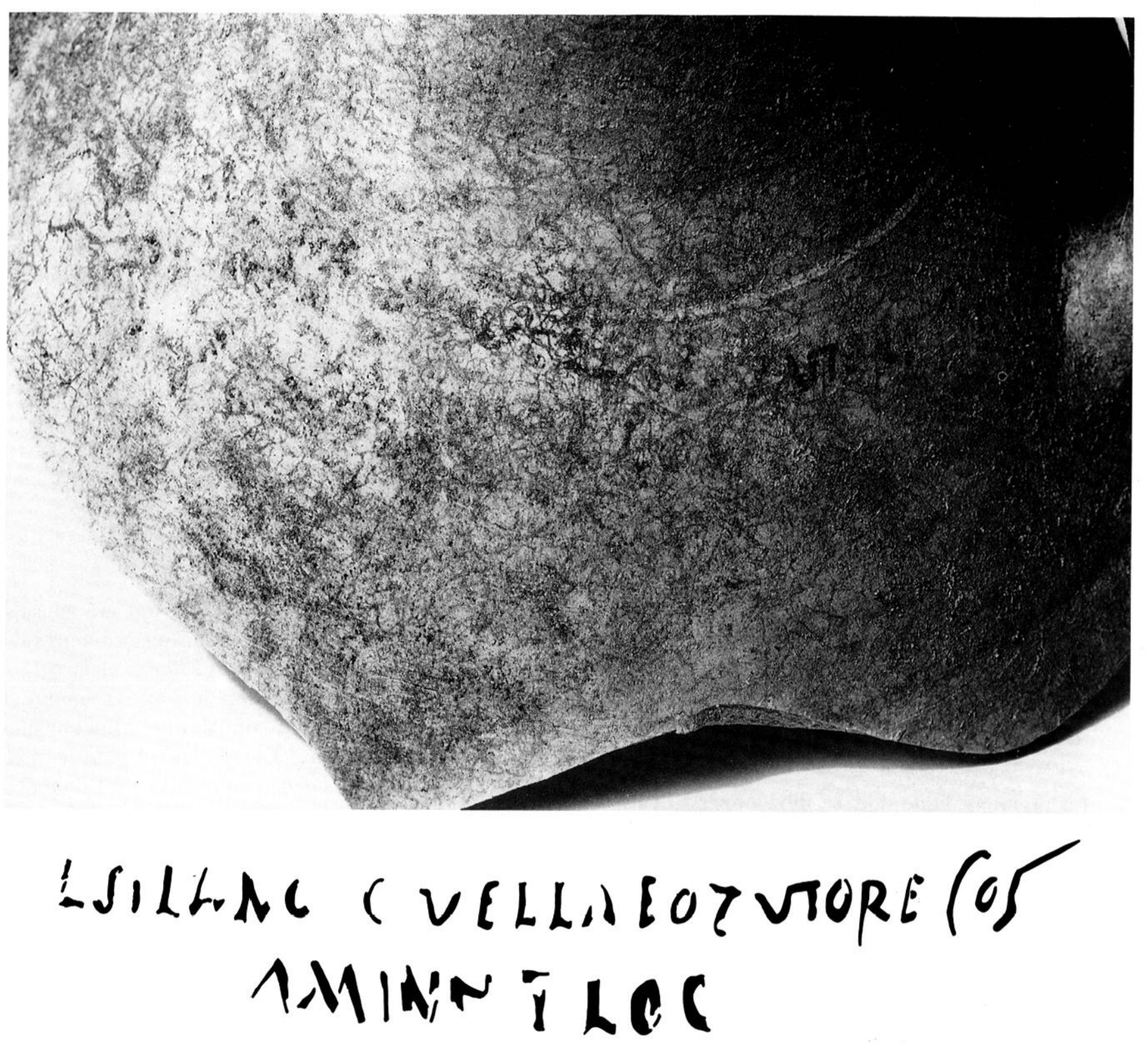

Fig. 25 - Amphore gauloise du sondage F (SF.09) et marque peinte sur le col. (Échelle 1/1).
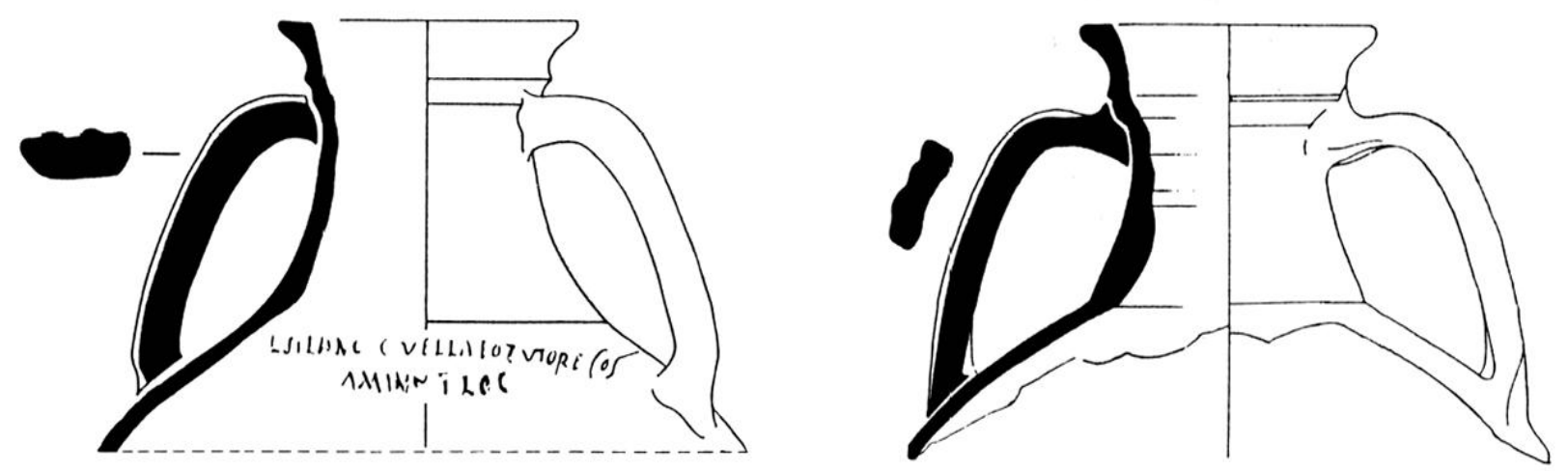

Fig. 26 - Comparaison des cols de deux amphores gauloises fréjusiennes à lèvre à double inflexion externe : à gauche, col du sondage F (SF.09); à droite, col de l'Argentière. (Échelle 1/4). 
tions d'Aspiran, de Velaux et de Fréjus ${ }^{10}$. Pour Fréjus, elle s'est fondée sur l'analyse de la pâte d'un col non pas "trouvé dans la vallée de l'Argens", mais issu de la fouille de l'Argentière ${ }^{11}$, analyse qui conclut à une fabrication locale : l'argile est pratiquement identique à celle des productions de l'atelier du Pauvadou ${ }^{12}$. Ce col de l'Argentière est, ainsi qu'on le verra en comparant photographies et dessins ${ }^{13}$, tout à fait semblable à celui de l'amphore de la Porte d'Orée (fig. 26). Il devrait donc s'agir d'une amphore foro-julienne, bien que le lieu précis de fabrication ne nous soit pas encore connu. I)̀s lors la date de 28 après J.-C., intéressante déjà dans la mesure où une date absolue est chose rarissime dans une fouille, et où elle contribue à la datation de l'état IA des installations portuaires de la Porte d'Orée, prend son importance pour l'établissement d'une chronologie de la production des ateliers

10 F. LAtBenhemer, La production des amphores en Gaule Varbonnaise. Annales Littéraires de l'Université de Besançon, 327. Paris, Les Belles Lettres, 1985, p. 302-307. On verra, supra p. 2:35, qu'elle préfère maintenant détacher les amphores de Fréjus du type "G7".

11 Sens de la mention ARG1 portée sur l'objet. Sur les fouilles de l'Argentière, ef. Chr. Gocdinfal, Informations archéologiques : Côle d'Azur. Gallia, 35, 1977, p. 497-498 et 37. 1979 , p. 555-557.

12 P. Fontes, F. Laubenheimer, J. Lebianc, F. Bonnffoy, K. Grter., F. Widfmann, Nouvelles données analytiques et typologiques sur les ateliers de production d'amphores en Gaule du Sud, in : $20^{\circ}$ Symposium international d'archéométrie, Paris 26-29 mars 1980, Revue d'Archéométrie, 3. 1981, p. 95-110.

13 Photo (déjà publiée par F. Laubenheimer) et dessin (inédit) de l'amphore de l'Argentière m'ont èté confiés par Daniel Brentchaloff, que je remercie très amicalement. d'amphores : elle confirme, d'une part, ce qu'avait fait apparaître, pour le même type, l'étude de l'atelier d'Aspiran, producteur de " $G 7$ " entre 20 et 30 de notre ère ${ }^{14}$; elle apparaît d'autre part comme précoce, plus ancienne sans doute qu'on ne l'avait jusqu'ici constaté, pour la production des amphores à Fréjus, et pour l'exportation de vin du terroir: la ligne 2 de l'inscription peinte, en effet, porte le nom du cépage aminn(eum) ${ }^{15}$ que le mot suivant qualifie probablement comme un cru; la dénomination, cependant, nous échappe. L'amphore était probablement destinée à l'exportation et a été cassée en gagnant le port ou dans un entrepôt proche du port. Le nom du commerçant exportateur, qui sans doute aurait pris place sous celui du contenu, n'y figurait pas encore.

B. L.

14 P.-Y. Gentr, J.-L. Fichrs, Latelier de potiers gallo-romain d'Aspiran (Hérault). Synthèse des travaux de 1971 à 1978, Figlina, 3, 1978, p. 75-77.

15 Quatorzième mention, à ma connaissance de l'A minneum sur des amphores de Gaule méridionale : 9 à $F_{0}$ s (B. Liol, R. Marichal, Les inscriptions peintes sur amphores de l'anse Saint-Gervais a Fos-sur-Mer, Archaeonautica, 2, 1978. p. $145 s q, n^{\circ} 36$ et 37 et p. 179-181, no 81 : - B. Liou, Les épaves de Tarraconaise da chargement d'amphores Dressel 2-4. Archaeonautica, 7, 1987, p. 72 sq, F103-107 et F111); 3 a Lyon (A. Desbat, R. Lequément, B. Llou, Inscriptions peintes sur amphores : Lyon et Saint-Romain-en-Gal, Archaeonautica, 7 . 1987, p. 142-145, L1-3); 1 à Toulon (inédite, fouilles 1987). Sur l'Aminneum, voir les commentaires de B. Liov et R. MARIснат, ibid., p. 145 et 176 et de B. Lrov, ibid., p. 76 et 78 . 


\section{BIBLIOGRAPHIE}

Aldini T.

1978: Anfore Foropopiliensi, Archaeologia Classica, XXX, p. 236-245.

\section{Allmer A.}

s.d. : Inscriplions de Vienne, IV, Lyon.

Allmer A., Dissard P.

1887-1888: Trion. Anliquilés découvertes en 1885, 1886 et antérieurement au quartier de Lyon dit de Trion, Lyon.

Bacou J.-P., Bacou A.

1982-1983 : L'oppidum de Montfau à Magalas, Hérault (19631979), Archéologie en Languedoc, 5, p. 61-114.

Becker C., Constantin C., Desbat A., Jacquin L., Lascoux J.-P. 1986 : Le dépôt d'amphores augustéen de la rue de la Favorite à Lyon, Figlina, 7, p. 65-89.

Beltrán Lloris $\mathbf{M}$.

1970 : Las anforas romanas en España, Saragosse, $669 \mathrm{p}$.

Béraud I., Gébara Ch., Landuré C.

1991 : La Porte d'Orée : transformations et avatars d'un secteur portuaire à Fréjus (Var), Gallia, 48, p. 165-228.

Brentchaloff D.

1980 : L'atelier du Pauvadou, une officine de potiers flaviens à Fréjus, Revue Archéologique de Narbonnaise, XIII, p. 73-114.

1988 : L'amphore à saumure de type Fréjus-lenzbourg, in: Sociëté Française pour l'Élude de la Céramique Antique en Gaule (SFECA(i), Actes du Congrès d'Orange, 12-15 mai 1988, p. 179186.

Brentchaloff D., Picon M.

1990 : Amphores de Fréjus-Lenzbourg : origine contrôlée, in : SFECAG, Actes du Congrès de Mandeure-Mathay, p. 225-230.

\section{Bruhl A.}

1964 : Girconscription de Lyon, Lyon, La Solitude, Gallia, 22. p. 413.

Brun J.-P., Guimelli P., Obert G., Quinn G.

1984 : Les marques sur tuiles romaines de la côte des Maures (Var), Bulletin Archéologique de Provence, 14, p. 13-17.

\section{Carre M.-B.}

1985: Les amphores de la Cisalpine et de l'Adriatique au début de l'Empire, MEFRA, 95, I, p. 207-245.

\section{Carre M.-B., Cipriano M.T.}

1985 : Le anfore, Saggi di Scavo a Sevegliano, Aquileia Nostra. p. 6-24.

Colls D., Etienne R., Lequément R., Liou B., Mayet F. 1977 : L'épave de Port-Vendres II el le commerce de la Bétique à l'époque de Claude, Archaeonautica. 1, 143 p., 55 fig.
Corsi-Sciallano M., Liou B.

1985: Les épaves de Tarraconaise à chargement d'amphores Dressel 2;4, Archaeonautica, 5, 178 p., 126 fig., tabl.

\section{Delattre R.P}

1894 : Le mur d'amphores de la colline St-Louis à Carthage, Bulletin Archéologique du Comité des Travaux IIisloriques et Scientifiques, p. 89-119.

1907 : Un second mur d'amphores découvert à Carthage, Bulletin de la Socièlé Archéologique de Sousse, p. 33-49.

Desbat A., Picon M.

1986 : Les importations d'amphores de Médilerranée orientale à Lyon (fin $\mathrm{re}^{\mathrm{r}}$ siècle avant $J .-C$. et rer siècle après), XIII" suppl. au Bulletin de Correspondance Hellénique, p. 637-648.

Donnadieu Dr., Vadon Dr.

1926-1928 : Le vivier maritime gallo-romain de La Gaillarde près Saint-Aygulf, Institut des Fouilles de Provence el des Préalpes. Bulletin et Mémoire, I, p. 225-230.

\section{Dressel $\mathrm{H}$.}

1879 : Di un grande deposito di anfore rinvenuto nel nuovo quartiere del Castro Pretorio, Bulletino della Commissione Archeologica Comunale di Roma, 7, p. 36-112.

\section{Euzennat $M$.}

1969 : Provence-Côte d'Azur-Corse, Gallia, 27, p. 421.

\section{Février P.-A.}

1973: Fréjus (Forum Julii) el la basse vallèe de l'Argens, Cuneo, Institut international d'ètudes ligures, 205 p., 121 fig.

Fontes P., Laubenheimer F., Leblanc J., Bonnefay F., Gruel K.. Widemann F.

1981 : Nouvelles données analytiques et typologiques sur les ateliers de production d'amphores en (raule du Sud, in: 20 Symposium international d'archéométrie, Paris 26-29 mars 1980, Revue d'Archéométrie, 3, p. 95-110.

\section{Goudineau Chr}

1981: Une fouille de sauvetage aux Aiguières, Les Dossiers, Archéologie el Histoire, 57, p. 52-54.

1982: Une fouille récente à la périphérie de Forum Julii : le chantier des Aiguières, CRAI, avril-juin, p. 279-292.

\section{Grace V.}

1979: Amphoras and the Ancient Wine Trade, Princeton, non pagine. 69 fig. 
Helly B., Le Bot-Helly A., Liou B.

1986: In dépòt d'amphores Dressel 20 à inscriptions peintes découvert à Sainte-Colombe (Rhòne), Archaeonautica, 6 . p. 121-145.

Hesnard A.

1980 : Ln dépòt augustéen d'amphores à La Longarina, Ostie. in : Roman Seaborne Commerce, Memoirs of the American Academy in Rome, XXXVI, p. 141-156.

Hesnard A., Carre M.-B., Rival M., Dangréaux B.

1988: L'épave romaine Grand-Ribaud I) (IHyères, Var), Archaeonautica, 8, $182 \mathrm{p} ., 56 \mathrm{pl}$.

Hesnard A., Ricq M., Arthur P., Picon M., Tchernia P.

1989 : Aires de production des gréco-italiques et des Dr. 1, in : Amphores romaines et histoire économique: dix ans de recherches. Actes du colloque de Sienne, 22-24 mai 1986, Collection de l'École Française de Rome, 114, p. 21-65.

Jacob J.-P., D’Anna A., Denante S., Guilcher A., Pagni M. 1987-1988 : Provence-Alpes-Côte d'Azur, Gallia Informations, 2 , p. 185-343.

Laubenheimer F.

1985: La production des amphores en Gaule Narbonnaise. Annales Littéraires de l'Université de Besançon, 327, Paris, Les Belles Lettres, 466 p., 202 fig., 29 tabl.

1989 : Les amphores gauloises sous l'empire : recherches nouvelles sur leur production et leur chronologie, in: Amphores romaines et hisloire économique : dix ans de recherches. Actes du colloque de Sienne, 22-24 mai 1986, Collection de l'École Française de Rome, 114, p. 105-138.

1990 : Le temps des amphores en Gaule, Vins, huile et sauces, Paris, Éd. Errance, 192 p., 174 fig., 18 cartes et plans.

Lemoine C., Meille E., Poupet P., Barrandon J.-N., Borderie B. 1981 : Étude de quelques altérations de composition chimique de céramiques en milieu marin et terrestre, in : $20^{\circ}$ Symposium international d'archéométrie. Paris 26-29 mars 1980, Revue d'Archéométrie, 3, p. 349-360.

Liou B., Corsi-Sciallano $\mathbf{M}$.

1989 : Le trafic du port de Fos dans l'Antiquité : essai d'évaluation à partir des amphores, in : SFECAG. Actes du Congrès de Lezoux, 4-7 mai 1989, p. 153-167.

\section{Mc Cann A.M.}

1987 : The Roman Port and Fishery of Cosa, Princeton, 353 p., XIX fig., 14 plans.

Martin-Kilcher S.

1987 : Die römischen Amphoren aus Augst und Kaiseraugst, 1 , Die südspanischen Olamphoren (Gruppe 1), Augst, 311 p., 119 fig., $94 \mathrm{pl}$.

1990 : Le vin de la Suisse romaine, in: Archéologie de la vigne et du vin, Actes du colloque, 28-29 mai 1988, Caesarodunum, 24. p. 175-204.

Meffre J.-C. et Mefre P.

à paraître : L'atelier augustéen d'amphores et de céramiques de Sainte-Cécile-les-Vignes (Vaucluse), in: Les amphores en Gaule: production et circulation, Actes de la Table-Ronde de Metz, 4-6 oct. 1990.

\section{Müller A.}

1981: Vieille-Toulouse : le fond d'habitat IV à La Tuilerie. in: Structures d'habitat à l'Age du Fer en Europe lempérée. Paris, p. 129-138.

\section{Narbonne et la mer}

1990 : Y. Solier (préface) et groupe ANTEAS. Narbonne et la mer, catalogue de l'exposition. Narbonne, p. 80-81.

Panella C.

1973 : Anfore, Oslia III, Studi Miscellanei, 21, Rome, De Luca, 696 p., L pl.

Pasqualini M

1988 : Céramiques dans le bassin de l'Argens et la région de Fréjus (Var) entre le $\mathrm{I}^{\mathrm{er}}$ et le III" siècle de notre ère. Les productions régionales, in : SFECAG, Actes du Congrès d'Orange, 12-15 mai 1988 , p. 155-168.

Pesavento Mattioli S.

1990 : Anfore per la bonifica, Archeo, 60, p. 15.

Pélichet E.

1946 : A propos des amphores romaines trouvées à Nyon, Zeitschrift für schweizerische Archaeologie und Kunstgeschichte, 8, p. 189-202.

Picard C.

1959 : Informations archéologiques. Circonscription de Paris (sud), Gallia, 17, p. 299-309.

Picon M.

1987 : La fixation du baryum et du strontium par les céramiques, Revue d'Archéométrie, 11, p. 41-47.

Py $\mathbf{M}$.

1988 : Sondages dans l'habitat antique de Lattes. Lallara, I. p. $65-146$.

\section{Reddé M}

1986 : Mare Nostrum. Les infrastruclures, le dispositif et l'histoire de la marine militaire sous l'Empire romain, BEFAR, 260 . 737 p., fig., h.-t.

\section{Revue Épigraphique}

1902 : 1479, Marques d'amphores, Sainte-Colombe-les-Vienne.

Reynaud J.-F., Lasfargues J., Desbat A.

1973: Lne fouille de sauvetage à Lyon, Archeologia, 60, p. 73-74.

Roux J.-C., Verdier F.

1989 : L'utilisation du sable dans l'habitat antique de Lattes, Latlara, 2, p. 33-38.

Salviat F.

1972 : Circonscription de Provence, Gallia, 30, p. 511-541.

Van der Werff $\mathrm{J}$.

1986 : The Amphora Wall in the House of the Porch, Ostia, BABesch, 61, p. 96-137.

Vassy $\mathrm{A}$.

1914: Rapport sur la découverte de trois gisements damphores romaines à Sainte-Colombe-les-Vienne, Comptes-rendus de l'Association Française pour l'Avancemenl des Sciences. Congrès du Ilavre, p. 1-6.

Yule B.

1989 : Excavations at Winchester Palace, Southwark, London Archaeologist, 6, 2, p. 31-39.

Zevi F.

1966 : Appunti sulle anfore romane I. La tavola tipologica del Dressel, Archeologia Classica, XVIII, p. 229-247. 